Estuarine, Coastal and Shelf Science

February 2018, Volume 201, Pages 40-55

http://dx.doi.org/10.1016/j.ecss.2016.05.019

http://archimer.ifremer.fr/doc/00337/44845/

(c) 2016 Elsevier Ltd. All rights reserved.

\title{
Projecting changes in the distribution and productivity of living marine resources: A critical review of the suite of modeling approaches used in the large European project VECTORS
}

\begin{abstract}
Peck Myron A. ${ }^{1,{ }^{*}}$, Arvanitidis Christos ${ }^{2}$, Butenschön Momme ${ }^{3}$, Canu Donata Melaku ${ }^{4}$, Chatzinikolaou Eva ${ }^{2}$, Cucco Andrea ${ }^{5}$, Domenici Paolo ${ }^{5}$, Fernandes Jose A. ${ }^{3}$, Gasche Loic ${ }^{6}$, Huebert Klaus B. ${ }^{1}$, Hufnagl Marc ${ }^{1}$, Jones Miranda C. ${ }^{7}$, Kempf Alexander ${ }^{8}$, Keyl Friedemann ${ }^{8}$, Maar Marie ${ }^{9}$, Mahévas Stephanie ${ }^{6}$, Marchal Paul ${ }^{10}$, Nicolas Delphine ${ }^{11}$, Pinnegar John K. ${ }^{7}$, Rivot Etienne ${ }^{12}$, Rochette Sebastien ${ }^{13}$, Sell Anne F. ${ }^{8}$, Sinerchia Matteo ${ }^{5}$, Solidoro Cosimo ${ }^{4}$, Somerfield Paul J. ${ }^{3}$, Teal Lorna R. ${ }^{14}$, Travers-Trolet Morgane ${ }^{10}$, Van De Wolfshaar Karen E. ${ }^{14}$
\end{abstract}

${ }^{1}$ Institute of Hydrobiology and Fisheries Science, University of Hamburg, Olbersweg 24, 22767

Hamburg, Germany

${ }^{2}$ Hellenic Centre for Marine Research, Institute of Marine Biology, Biotechnology and Aquaculture, P.O. Box 2214, 71003 Heraklion, Crete, Greece

3 Plymouth Marine Laboratory, Prospect Place, The Hoe, Plymouth, PL13 DH, UK

${ }^{4}$ OGS Istituto Nazionale di Oceanografia e di Geofisica Sperimentale Borgo Grotta Gigante 42/C,

34010, Sgonico, TS, Italy

${ }^{5}$ CNR Istituto per l'Ambiente Marino Costiero (IAMC), Oristano, Loc. Sa Mardini, 09170 Torregrande, Italy

${ }^{6}$ IFREMER, Unité Ecologie et Modèles pour l'Halieutique, rue de L'ile d'Yeu, BP21105, 44311 Nantes, France

${ }^{7}$ Centre for Environment, Fisheries and Aquaculture Science, Lowestoft NR33 OHT, UK

${ }^{8}$ Thünen Institute, Institute of Sea Fisheries, Palmaille 9, 22767, Hamburg, Germany

${ }^{9}$ University of Aarhus, Department of Bioscience, Frederiksborgvej 399, PO Box 358, 4000 Roskilde, Denmark

${ }^{10}$ IFREMER, Laboratory Fishery Resources, 150 quai Gambetta, BP 699, 62321 Boulogne sur mer, France

${ }^{11}$ Sir Alister Hardy Foundation for Ocean Science (SAHFOS), The Laboratory, Citadel Hill, Plymouth, PL1 2PB, UK

${ }_{12}^{12}$ Agrocampus Ouest, UMR 985 ESE Ecologie et santé des écosystèmes, F-35042 Rennes, France

${ }^{13}$ IFREMER, Unité Dynamiques de I'Environnement Côtier, Laboratoire Applications Géomatiques, BP

70, 29280 Plouzané, France

${ }^{14}$ Institute for Marine Resources and Ecosystem Studies, Haringkade 1, ljmuiden, The Netherlands

*Corresponding author : Myron A.Peck, email address : myron.peck@uni-hamburg.de 


\begin{abstract}
:
We review and compare four broad categories of spatially-explicit modelling approaches currently used to understand and project changes in the distribution and productivity of living marine resources including: 1) statistical species distribution models, 2) physiology-based, biophysical models of single life stages or the whole life cycle of species, 3) food web models, and 4) end-to-end models. Single pressures are rare and, in the future, models must be able to examine multiple factors affecting living marine resources such as interactions between: i) climate-driven changes in temperature regimes and acidification, ii) reductions in water quality due to eutrophication, iii) the introduction of alien invasive species, and/or iv) (over-)exploitation by fisheries. Statistical (correlative) approaches can be used to detect historical patterns which may not be relevant in the future. Advancing predictive capacity of changes in distribution and productivity of living marine resources requires explicit modelling of biological and physical mechanisms. New formulations are needed which (depending on the question) will need to strive for more realism in ecophysiology and behaviour of individuals, life history strategies of species, as well as trophodynamic interactions occurring at different spatial scales. Coupling existing models (e.g. physical, biological, economic) is one avenue that has proven successful. However, fundamental advancements are needed to address key issues such as the adaptive capacity of species/groups and ecosystems. The continued development of end-to-end models (e.g., physics to fish to human sectors) will be critical if we hope to assess how multiple pressures may interact to cause changes in living marine resources including the ecological and economic costs and trade-offs of different spatial management strategies. Given the strengths and weaknesses of the various types of models reviewed here, confidence in projections of changes in the distribution and productivity of living marine resources will be increased by assessing model structural uncertainty through biological ensemble modelling.
\end{abstract}

Keywords : Distribution, Modeling, Habitat, Resources, Man-induced effects 


\section{Introduction}

Marine habitats provide resources critical for the wellbeing of society including food security and energy (Lam et al., 2012; Merino et al., 2012). For the effective stewardship of living marine resources, it is critical to understand the factors and processes that may have interacted to cause historical changes in distribution and productivity (Simpson et al., 2011; Sumaila et al., 2011; Blanchard et al., 2012). Furthermore, it is important to develop tools and approaches that provide robust projections of future changes (Metcalfe et al., 2012; Jørgensen et al., 2012), particularly within regional seas and their coastal habitats (Luisetti et al., 2011). Nearly one third of our burgeoning human population inhabits areas surrounding regional seas. Multiple drivers (e.g., the need to maintain food security, requirements to increase renewable energy sources, maintaining viable shipping routes) have made coastal areas and shelf seas hotspots of pressures (Doney, 2010) such as, the potential for over-fishing, increased nutrient runoff/inputs causing eutrophication, physical alteration/loss of marine habitats, continued risk of introduction and spread of invasive alien species). Given the diversity of anthropogenic activities and effects, the development of tools that can examine the interaction among various pressures such as climate and overfishing (Perry et al., 2010; Griffith et al., 2012), will be important for projecting impacts and providing effective management advice for living marine resources.

Changes in the productivity and changes in the distribution of a species are likely to be strongly coupled (Blanchard et al., 2011) but the processes causing the former and latter may differ. Patterns in distribution result from interactions between physical (ocean currents / inflow, temperature, salinity, or substrate type) and biological processes (e.g., predator-prey relationships, competition) and both are influenced by anthropogenic activities. Changes in the distribution of marine organisms, including shifts towards higher latitudes or deeper waters in response to ocean warming, are well documented (Rijnsdorp et al., 2009 and Sunday et al., 2012, Hiddink et al., 2015). At temperate latitudes, these shifts are associated with the appearance of Lusitanian fauna (organisms traditionally distributed in warmer waters) and reduced extent or loss of boreal species (Sunday et al., 2012). In most cases, species move (or disappear) from areas after critical thresholds in abiotic factors (temperature, salinity, dissolved oxygen and $\mathrm{pH}$ ) are exceeded (Pörtner and Peck, 2010 and Pörtner, 2012). In European waters and elsewhere, these climate-driven shifts (Beaugrand and Reid, 2003, Beare et al., 2004, Perry et al., 2005 and 
Rijnsdorp et al., 2009) as well as the increasing number of alien species introduced via ballast waters, released from aquaculture (Hulme et al., 2008) or migrating through man-made waterways such as the Suez Canal (Galil et al., 2014) are creating novel mixtures of species with unforeseen consequences to the structure and function of marine food webs (i.e. Hobbs et al., 2009).

In contrast to changes in distribution, changes in the productivity of a species can result from a mixture of trophodynamic (bottom-up and top-down) processes. Bottom-up processes can alter growth performance and the reproductive potential of adults (Marshall et al., 2000 and Kraus et al., 2002) as well as the rates of survival of their progeny (e.g. Sundby, 2000) whereas top-down processes can regulate lower trophic levels (Shurin et al., 2002 and Mueter et al., 2006). A further complication is that the strength of these various trophodynamic processes can be influenced by changes in key abiotic factors on species such as changes in life history scheduling and match-mismatch dynamics between predators and their prey resources (Clark and Frid, 2001, Hunt et al., 2002, Beaugrand et al., 2003 and Kempf et al., 2013). It is critical to track changes in the productivity of different populations since changes in productivity of local populations can be misinterpreted as an active migration of species to higher latitude (Petitgas et al., 2012a).

A variety of modelling tools has been utilized to examine historical changes in distribution and/or productivity of living marine resources (Figure 1). Often designed for specific objectives, these tools differ markedly in complexity, from simple statistical descriptions of trends in historical field data to more complex physiological models attempting to understand the mechanisms underlying habitat requirements of species, trophic groups or any other kind of assemblage (Jørgensen et al., 2012). Another sub-set of modelling approaches has focused on providing spatially explicit representations of trophodynamic structure and function of ecosystems. Finally, the most complex, "end-to-end" models create virtual ecosystems incorporating industries, allowing trade-offs between various, competing economic sectors and activities (e.g., fisheries, renewable energy, conservation) to be examined in a management evaluation framework (Fulton et al., 2011). These various tools can offer insight, to a greater or lesser extent, on the mechanisms acting to cause historical changes in distribution and productivity of living marine resources and some allow projection of future trajectories. Plagányi (2007) provided a thorough review of the merits of various modelling tools in the context of ecosystem-based fisheries 
management, Travers et al. (2007) provided a retrospective on various modelling approaches leading to the design of size-based food web and end-to-end models, and, Hayder et al. (2015) reviewed 14 different ecosystem models currently operational in the UK with regard to their applicability to provide advice on five sets of policy questions including spatial management issues in the North Sea and NE Atlantic.

In this study, we compared four modelling approaches developed to estimate changes in the distribution and/or productivity of living marine resources. The suitability of each method for understanding and projecting changes that arise from interacting drivers is also discussed. Model approaches considered were: 1) statistical modelling of habitat associations including bioclimate envelope models; 2) biophysical models of single species and/or life stages; 3) spatially explicit food web models; and 4) end-to-end models. Some of these approaches rely heavily on the statistical analysis of historical observations (1), while others are coupled physical-biological models that either include $(2,3,4)$ or may exclude (2) food web interactions. Examples of interacting state changes (and their pressures) include warming and acidification (climate change), decreases in concentrations of dissolved $\mathrm{O}_{2}$ and changes in suspended particulate matter (eutrophication), changes in food web composition (introduction of alien invasive species), and reductions in biomass of stocks/populations (fisheries exploitation). We provide a few examples of applications of these various modelling approaches with emphasis on European regional seas, comment on the strengths and weaknesses of those models, and recommend new avenues to strengthen modelling tools.

\section{Statistical Analyses and Species Distribution Models}

\subsection{Retrospective Exploration of Shifts in Distribution and/or Productivity}

Statistical models incorporating spatially-explicit data on prey/predators or physical factors can reveal factors having a major influence on spatial and/or temporal changes in distributions of taxa. For example, Llope et al. (2012) applied spatially-explicit threshold generalized additive models (GAMs) to examine spatio-temporal variability and interactions among various plankton groups in the North Sea, using Continuous Plankton Recorder (CPR) data. This study revealed a shift in the reliance of filter feeding zooplankton from diatoms to dinoflagellates in the early 1970s that was only apparent in eastern regions of that shelf sea ecosystem. These models identify major spatial and temporal changes in distributions of taxa which can be used for 
integration in other models or presented as maps. These types of statistical models can help identify which factors have exerted the most influence on determining the spatial and/or temporal distribution of species in the past (e.g., Kempf et al., 2013 and Nicolas et al., 2014).

\subsection{Species Distribution Models: Present and Future Distribution and Abundance}

A number of relatively simple models have been developed in the past that usually do not include population dynamics but are based on regression techniques. Such models are the species distribution models (SDMs). The simplest form of SDMs is the geo-statistical approaches that utilize spatial-autocorrelation (e.g. Hengl, 2009). Another form of SDMs is based on the habitat niche concept (Figure 2) and relates a biological response such as changed in occurrence or abundance to physical conditions. Ideally, these SDMs should also include species interactions (Soberón, 2007). These models produce pseudo-mechanistic understanding on the processes that govern distribution.

Bioclimatic envelope models are a specific type of SDM which have become commonly used to predict current, and to project future distributions and relative abundances of marine fish and invertebrates (e.g., Pearson and Dawson, 2003, Cheung et al., 2009 and Fernandes et al., 2013a). These and other SDMs examine the relationship between key climatic variables and species' presence / absence using (for the most part) historical distribution data (i.e. they are largely correlative). By looking at the current range of environmental conditions tolerated by a species, it is assumed to be possible to project future distributions given estimates of how the physical environment in an area will change in the future. These approaches have been applied to all sorts of marine organisms ranging from pathogens to seabirds, and including commercial fish (Phillips and Dudík, 2008).

Jones et al. (2012) examined the role of structural uncertainty (model type) by comparing the skill of three different SDMs, each with different assumptions and methods, to predict the distribution of fishes in the North Sea. Overall, the three types of SDMs did not vary greatly in their predictions of area or extent of occurrence for each species, but detailed patterns and values of predicted suitability within the extents of occurrence differed (Jones et al., 2012). A similar comparison has also been made for global projections (Jones and Cheung, 2014). Since these techniques do not require extensive field data sets, SDMs have also provided projections of 
future expansion of invasive species in Europe such as the Chinese mitten crab (Eriocheir sinensis) (Herborg et al., 2007) and the Pacific oyster (Crassostrea gigas) (Jones et al., 2013). One can question the use of SDMs for this purpose since the rate of the spread of an invasive alien species will depend upon life history characteristics (e.g., larval dispersal mechanisms and geographical range) which cannot be adequately assessed without additional modules. However, new SDM paradigms have emerged such as the Dynamic Bioclimate Envelope models (DBEMs) which are hybrids between purely statistical and mechanistic models. DBEMs incorporate simple functions allowing aspects of the ecophysiology, population dynamics as well as species interactions and dispersal of larvae and adults to be represented (Cheung et al., 2009 and Fernandes et al., 2013a). Despite their origins as statistical SDMs, the DBEMs are a good example of models which bridge different categories discussed later in this review (e.g. physiology-based or size-spectrum models)

\subsection{Strengths and Weakness (Statistical Approaches)}

The first strength of SDMs is that they have a standard set of diagnostic tools and procedures to evaluate model performance and predictive skill (Pearce and Ferrier, 2000 and Thuiller, 2003). In most cases independent test datasets are lacking, but other methods exist to make internal assessments such as using only a certain percentage of data for model training (Fielding and Bell, 1997). In addition, validation methods are now testing whether/how well model results represent observed biological responses such as latitudinal shifts and/or trends in total biomass (Fernandes et al., 2013a). A second perceived strength of SDMs is that they do not require extensive information from laboratory studies or physical (hydrodynamic) models representing future patterns in ocean currents.. Rather, the approach can be applied to many different species, in different areas of the world - as long as some information is available on occurrence (including only sporadic 'sightings') as well as appropriate datasets of environmental variables.

These statistical models are an essential step along the path from pattern recognition (what, where, when) to process understanding (how, why). However, they are fundamentally based on correlations and do not provide a mechanistic, cause-and-effect understanding. The future may include novel combinations of abiotic and biotic factors making it necessary to extrapolate beyond historical observations. Moreover, anthropogenic activities result in non-stationarity 
within natural systems, such that fluctuations and variability noted in the past are unlikely in the future (Milly et al., 2008). The increase in the frequency of extreme events observed in recent years and projected for the future by climate models, helps illustrate this point (IPCC, 2013). Sugihara et al. (2012) demonstrated the pitfalls of using correlative approaches by applying nonlinear state-space reconstruction to distinguish causality from correlation in long-term fluctuations of anchovy and sardine populations in the California current. In that case, the strength of the effect of temperature on sardine depended on the state of the system, and, therefore, current management decisions using a fixed temperature index for sardines appear inadequate (Sugihara et al., 2012).

Given the widespread use of SDMs across the globe, particularly DBEMs in marine systems, it seems important to highlight potential avenues for improvement. Huntley et al. (2010) presented a grid-based model for the distribution of terrestrial vegetation which includes various modules simulating: 1) climatic suitability, 2) habitat suitability, 3) population dynamics, and 4) dispersal. Those and other authors (e.g. Anderson et al., 2009) point out that models integrating these four components are still in their infancy. Understanding how the inherent physiology of the target organisms, such as thermal tolerance windows (Pörtner and Peck, 2010 and Jørgensen et al., 2012), is impacted by interacting drivers can be used to parameterize the first (climatic suitability) module. The second (habitat) module takes into account key attributes of a species' niche which, for marine species, could be bottom sediment type, turbidity, depth (etc.) and is where the effects of other drivers (e.g. eutrophication) could be implemented. The third and fourth modules simulate population dynamics (either mechanistically or statistically) using functions incorporating key environmental factors. These latter two modules have been included in the DBEMs developed by Cheung et al. (2011) which also included equations describing larval advection and dispersal and survival (O'Connor et al., 2007). The ongoing steps to include physiological principles in the model developed by Cheung et al. (2011) are similar to those outlined by Huntley et al. (2010) for terrestrial organisms.

\section{Physiology-based and Biophysical Models}

Incorporating physiology into spatial models of habitat characteristics may provide a mechanistic, cause-and-effect understanding of observed changes in productivity and distribution of organisms such as fishes (Pörtner and Peck, 2010). The benefits of using ecophysiological 
measurements to shed light on how environmental change affects species and their ecosystems (and to project future changes) is evidenced by the growth of the discipline termed "conservation physiology" (Seebacher and Franklin, 2012). A practical example of how physiological measurements can be used to inform policy is provided by Cooke et al. (2012) who describe applications relating to fisheries and gear interactions, disease and health and climate-driven warming in various Pacific salmon (Oncorhynchus spp.) species in the Fraser River Basin.

In terms of modelling the distribution and abundance of fishes and other living marine resources, Jørgensen et al. (2012) outlined how physiological knowledge could be infused at every level of model complexity (e.g., from global models of general patterns to models of individuals within local habitats) to refine predictions. They highlighted how metabolic (aerobic) scope (a measure of the amount of oxygen potentially available to animals to fuel activities beyond those required for maintenance) provides a general framework for examining the potential effect of interacting stressors (e.g., reductions in ambient $\mathrm{O}_{2}$ concentration due to eutrophication, climate-driven warming, reductions in $\mathrm{pH}$ due to ocean acidification) on the fitness and performance of animals. Fry $(1957,1971)$ proposed using metabolic scope as a framework for examining interacting stressors many decades ago (Figure 3). Based upon new measurements made at the cellular, tissue and organismal level, metabolic scope has been re-introduced as a general framework (Pörtner and Knust, 2007, Pörtner and Peck, 2010 and Pörtner, 2012). The effect of interacting environmental factors on the metabolic/aerobic scope of individuals is now being used (either directly or indirectly) in a variety of models projecting changes in the distribution and productivity of populations (Cucco et al., 2012; Teal et al., In Press). Cucco et al. (2012) provided a thorough description of how estimates of aerobic scope can be coupled to physical models to understand how temperature and ambient oxygen concentration interact to influence habitat suitability. Importantly, Cucco et al. (2012) demonstrated how seasonal migration patterns are coupled to physiological tolerance and to changes in habitat suitability, underscoring the need for models to capture not only long-term average characteristics but also the short-term dynamics of the physical environment. The latter will be particularly important to evaluate competitive interactions resulting from novel species mixtures such as invasive alien species.

\subsection{Plankton and Early Life Stages of Fish}


The coupling of physical and biological models for early life stages of marine fish was considered a landmark achievement in terms of creating tools to generate and test hypotheses about processes affecting early survival and growth (Werner et al., 2001). Physical (hydrodynamic) models with Lagrangian particle-tracking subroutines have examined how changes in ocean circulation may influence the transport and distribution of plankton. For example, coupled hydrodynamic and individual-based models (IBMs) have become popular tools for investigating processes affecting distributions and productivity of marine fish species (Peck and Hufnagl, 2012). In short, biophysical early life stage IBMs have been created to examine how environmental characteristics affect the distribution, growth and/or survival of the larvae of many different fishes species. The structure and complexity of these biophysical models range from "simple" drift models including predator vulnerability and temperature-dependent larval growth functions to parameter-rich, physiology-based foraging and growth subroutines. The latter, more complex, models have been coupled to lower trophic level models (e.g., NPZD, nutrient, phytoplankton, zooplankton, detritus models) to represent how climate-driven changes in physical forcing can affect larval growth and survival both directly (via temperatures, and drift routes) and indirectly (by changes in the magnitude and timing of prey production) (Daewel et al., 2008, 2011, Figure 4). Size-spectrum modelling (discussed in a later section) provides a relatively simple method of constructing prey fields for higher trophic levels from model-derived estimates of bulk plankton carbon. Suitable habitats are those that have the appropriate combinations of physical (hydrodynamic) and biological (prey and predator field) characteristics (Kühn et al., 2008 and Daewel et al., 2011).

\subsection{Full life-cycle models}

It should be recognized that, in many cases, predicting changes in the productivity and distribution of marine species will not be possible without taking into account processes acting on all life stages (Petitgas et al., 2012b and Peck et al., 2013). Separate habitats are often used for spawning, as larval and juvenile nurseries, and for feeding by larger juvenile and adult fish and, due to differences in developmental morphology and physiology, different life stages are susceptible to different anthropogenic pressures to different degrees (Rijnsdorp et al., 2009 and Pörtner and Peck, 2010). A clear example is the different habitats required by different life stages of many temperate marine flatfish species, which include offshore banks (spawning), nearshore 
shallow waters (young juveniles) and offshore deeper waters (feeding areas) (Petitgas et al., 2012b). Rochette et al. (2013) developed a full lifecycle model for sole (Solea solea) in the Eastern Channel which included different modules representing key processes acting in specific, spatially separated habitats including: 1) a population model for adults, 2) a Lagrangian drift model for eggs and larvae settling to different near-shore nursery areas, and 3) a juvenile habitat suitability model (Figure 5). The model was built within a hierarchical Bayesian modelling framework, a valuable approach for embedding complex demographic models within statistical models using various (often noisy and incomplete) sources of data. The approach also appraises the uncertainty of estimates and predictions (Thomas et al., 2005 and Parent and Rivot, 2012).

The model framework described by Rochette et al. (2013) allows various interacting pressures to be examined, including fisheries-induced changes in adult demographics, climate-driven variability in drift routes of pelagic larvae, and coastal habitat degradation (via aggregate extraction, dredging, etc.) within juvenile nursery areas. It has the potential to provide tools capable of predicting the effect of spatial management measures. This coupled model approach produced reliable, unbiased and precise estimates of time series of abundance-at-age (and total recruitment), and of fishing mortality-at-age, with low bias and uncertainty. Simulations performed by Rochette et al. (2013) were also able to estimate the different carrying capacities of coastal nursery grounds, despite missing data and misspecification of larval drift. Currently the approach does not include explicit trophic interactions, but the Bayesian framework could incorporate this information, throughout the life cycle, using estimates from correlations, expert knowledge, or other sources of data.

\subsection{Physiologically-based Life-cycle Models}

Physiological-based modelling of species life cycles is an exciting, rapidly developing field. Balanced bioenergetics budgets, including parameters for energy gain (prey consumption and growth) and energy loss (metabolism and assimilation efficiency of food), and the effects of temperature and prey availability, have been linked to models of the physical environment and used to test the suitability of habitats for living marine resources such as bivalve molluscs (e.g., Solidoro et al., 2000) and juvenile and adult fish (Hanson et al., 1997; Durbin and Durbin, 1998; and Rose et al., 1999). In recent years there has been an upsurge in the utilization of Dynamic Energy Budget (DEB) models (Kooijman, 2010). Nisbet et al. (2012) provided a thorough 
comparison of the "theory-driven" DEB and the traditional, "data-driven" bioenergetics parameters. In a DEB model, energy flow between the sources (gains), sinks (losses), and state variables (reproductive buffer, structural body, etc.) is described by various processes allowing the effects of changes in key environmental parameters to be examined with respect to resource partitioning, such as the timing and magnitude of spawning (Figure 6). DEB models have been parameterised for various life stages of invertebrates and fish (van der Veer et al., 2009 and Freitas et al., 2011). In one example, Teal et al. (2012) used spatially-explicit estimates of the availability of benthic prey from a model (GETM-ERSEM-BFM (Stips et al., 2004)) and a DEB to examine the effects of climate variability by comparing suitable habitats for both flatfish species. The model captured well-known, ontogenetic shifts in depth distributions as well as the migration of juveniles towards deeper waters in the North Sea (and outside the protection of the "plaice box" closed area) associated with warming.

Full life-cycle models of interacting species now exist (e.g., Huse and Ellingsen, 2008 and Rose et al., 2015) representing the current state-of-the-art in mechanistic modelling of species movements (including behavioral adaptation and emergent life history patterns) and species interactions. These coupled biophysical, physiology-based approaches will allow resource managers to take advantage of the developing capacity of global climate models to project future, regional ocean conditions (Stock et al., 2011). Various, physiological, full life-cycle models exist, including models that embed a species within simplified lower (prey) and upper (predator) food webs. Two Pacific examples include SEAPODYM for tuna species (Lehodey et al., 2008) and NEMURO-Fish for Pacific herring (Clupea pallasii) and saury (Cololabis saira) (Kishi et al., 2011). These coupled, full lifecycle models have been used to answer key management questions. An invertebrate example includes exploring how management measures in the Venice Lagoon could offset losses to the aquaculture industry of the Manila clam (Ruditapes philippinarum) due to direct (temperature) and indirect (nutrients, prey) effects of climate change (Canu et al., 2010).

\subsection{Strengths and weaknesses of physiology-based life-cycle models}

Incorporating physiology into models is attractive because model estimates of changes in distribution and productivity are based on first principles with clearly defined mechanisms 
(causal not correlative). With DEBs as a notable exception, most bioenergetics-based budgets employ equations with different functional forms which make it impossible to make interspecific comparisons based on parameter estimates. In some cases, a lot of information is needed to parameterize these models and, due to a lack of physiological data, many/some applications of both DEBs and traditional bioenergetics models suffer from "parameter stealing" from one species to represent another. Furthermore, some models are strongly driven by the thermal tolerance range and the size-dependent optimal temperature for growth, which are often not known for species (Pörtner and Peck, 2010 and Freitas et al., 2011). An upsurge in measurements of organismal-level physiology is occurring, in part through research programs examining climate change and ocean acidification. The availability of these new data will aid in the development of physiology-based modelling approaches.

\section{Food web models}

\subsection{Models based on species and/or functional groups}

Anthropogenic changes in marine habitats are known to influence predator-prey dynamics (Altieri, 2008) and, hence, food-web models offer an important tool to assess potential changes in productivity or distribution resulting from such changes. For spatial investigations, Ecopath with Ecosim (EwE) (Christensen and Walters, 2004) has become a the most often employed modelling tool in a wide variety of applications from examining the effectiveness of marine protected areas in the Mediterranean Sea (Libralato et al., 2012) and English Channel (Metcalfe et al. 2015) to evaluating the multiple effects of climate and overfishing across 9 different marine ecosystems (Mackinson et al., 2009). Various models have been coupled to the EwE model including population models representing the dynamics of juvenile stages to better examine tradeoffs in ecosystem-based fisheries management options in the Gulf of Mexico (Walters et al., 2008), SDMs to create spatial representations of habitat quality and trophodynamic interactions (Christensen et al. 2014) and conservation planning software to examine interactions and tradeoffs between fisheries and conservation associated with different types of marine protected areas (Metcalfe et al. 2015). A second, flexible model representing food web dynamics is 'OSMOSE' (Object-oriented Simulator of Marine ecOSystems Exploitation) (Shin and Cury, 2001). OSMOSE simulates the vital rates (growth, mortality, feeding and reproduction) of super individuals (schools) that can move across a spatial grid (Figure 7). It is a multi-species model 
explicitly representing trophodynamic interactions between 10 to 20 species (depending on the ecosystem) and it also models the whole life cycle of fish from eggs and larvae up to juveniles and adults. Super individuals interact through opportunistic, size-based predation regulated by the extent of spatiotemporal co-occurrence and size adequacy of predators and their prey. Using this approach, no a priori food web or diet matrix are utilized, but these facets emerge from local trophic interactions which makes this model suitable for addressing effects of global changes on marine ecosystems (Travers et al., 2009).

OSMOSE has been applied to simulate the influence of Marine Protected Areas (Yemane et al., 2009), fishing moratoriums (Marzloff et al., 2009), overexploitation (Shin et al., 2004 and Travers et al., 2010), and the combined effects of climate change and overexploitation on the productivity and distribution of fishes. OSMOSE can be fully coupled with biogeochemical models (Travers et al. 2009) or forced by plankton and benthos distribution data (Marzloff et al., 2009). Similar to the larval fish IBM example, coupling lower and upper trophic level models allows climate-driven dynamics (via changes in bottom-up forcing) to be transferred up the food web and conversely top-down forcing to potentially propagate down to lower trophic levels. Spatiotemporal changes in the strength of biological interactions (e.g. predator-prey overlap) constitute the basis of OSMOSE and the latest versions of EwE (Hyder et al. 2015), making these models suitable for investigating how natural food web processes (predation and competition) may be altered in certain regions at certain times by fishing pressure and other forcing factors. Both OSMOSE and EwE (Pinnegar et al., 2014) have been used to examine the impact of invasive species on the distribution and abundance of living marine resources (Plagányi, 2007; Hayder et al., 2015).

\subsection{Size-spectrum Models}

Size is an important trait of marine animals governing predator-prey dynamics and some models have eliminated species in favour of size spectra (numbers of organisms versus their size) observed within marine ecosystems. Simple size spectrum models can distribute the biomass of marine organisms across multiple sizes, based on empirically observed patterns (Sheldon et al., 1972, Kerr and Dickie, 2001 and Jennings et al., 2008) or theoretical predictions (Platt and Denman, 1977, Kerr and Dickie, 2001 and Brown et al., 2004). Dynamic size spectrum models use a combination of empirical and mechanistic relationships to predict variability in the numbers 
of organisms within specific size bins. A size spectrum model can be used alone or coupled to other, species-specific models (Speirs et al., 2010 and Fernandes et al., 2013a). Fernandes et al. (2013a) employed a size-spectrum model based on Jennings et al. (2008) to incorporate species interactions to a DBEM for 48 fish species in the North Atlantic.

Size spectrum models have made an important, practical contribution to the advancement of models examining spatial dynamics of productivity and distribution of living marine resources by reduces model complexity. Size spectrum models are often applied in coupled models where they improve predictions of species interactions, particularly when species-specific information on vital rates is either missing or too complex to be included. For example, size spectrum theory was used by Daewel et al. (2008) to create zooplankton prey fields for larval fish from bulk carbon estimates of carbon obtained from a LTL model. Estimates of larval fish survival and growth appear to be quite sensitive to assumptions made regarding the slope of the size spectrum (Hufnagl and Peck, 2011). At the whole ecosystem level, a size spectrum food web model was coupled to a physical-biogeochemical model to predict the future effects of climate change on fish biomass and production in 11 large regional shelf seas (Blanchard et al. 2012). Analyses examined climate impacts with and without fishing effects and included bioeconomic modelling to estimate the impact of these changes on the global fisheries market (Merino et al., 2010). In this work, changes in fish production closely mirrored changes in phytoplankton productivity, underpinning the need to understand the effects of multiple drivers on the dynamics of lower trophic levels.

\subsection{Strengths and weaknesses of food web models}

Understanding the strength of food web connections is fundamental to projecting the response of ecosystems to anthropogenic perturbations, such as climate-driven changes in temperature regime or over-exploitation of living marine resources. Food web models are, therefore, an indispensable tool. However, these models require estimates of the extent of interactions between species including quantitative estimates of predator-prey relationships, which is a "data hungry" exercise. Furthermore, evaluating the impacts of the introduction of novel species requires extensive knowledge on the diet and suitability of these new species as prey prior to assessing potential impacts. Collecting stomach content data is time consuming and expensive and new diet data are needed (but not always available) to make robust estimates of the impacts of novel predator-prey 
dynamics (e.g., due to climate-driven shifts in species composition, abundance and distribution). The role of species that are not commercially important in the ecosystem is frequently unknown or only partly understood due to limited availability of broad-scale data on the abundance, distribution and diets of these ecosystem players (Garcia et al., 2003). A key example is ongoing efforts to use models to correctly depict the role of gelatinous species in marine food webs (Brodeur et al., 2011). On the one hand, size spectra models offer an approach to overcome a lack of detailed, species-specific data on feeding rates and diet preferences, but in situ data are needed to verify temporal and spatial changes in size spectra. On the other hand, predictions for individual taxa or species-specific responses are not possible, and those predictions are often the most important for informing advice on managemen.

\section{End-to-end models: Incorporating human sectors and pressures}

The term "end-to-end" reflects models that attempt to represent all trophic levels (from phytoplankton to fish and other top predators) with their physical environment (hydrography, biogeochemistry) and include the dynamics of human pressures (such as fisheries) affecting marine systems. This class of whole system models (e.g. Atlantis, InVitro) couples oceanography, biogeochemistry, food web, habitat, fish population and human sector(s) (e.g. fisheries, tourism, economics, coastal development, maritime traffic, etc.) in a dynamic way. While broad in scope, these models cover interacting processes and feedbacks of critical importance in marine and coastal systems (Fulton 2012). Their complexity does make them potentially unwieldy and they are often used for strategic (what) but not tactical (how) decisions. Plagányi (2007) and Hyder et al. (2015) discussed the ability of various models of marine ecosystems and fisheries to address different policy needs. Most models were only designed to examine a subset of the ecosystem in a very detailed way, some could examine changes in physical characteristics, but only a one or two (e.g. EwW, Atlantis) were deemed capable of providing estimates of the potential impacts of introduced species and habitat modification (see Hyder et al. 2005, their tables 2 and 3) .

ATLANTIS has been applied in many regions to consider fisheries, conservation, and multiple use management of marine and coastal resources (Fulton et al., 2011 and Morzari-Luna et al., 2012) including the exploration of potential impacts of climate change on natural resources and ecosystems (Fulton, 2011, Griffith et al., 2012 and Kaplan et al., 2012). Within European waters, 
ATLANTIS models are being developed for the eastern Channel, the North Sea, Baltic Sea and Strait of Sicily within the EU VECTORS project (VECTORS 2013))). Primary stressors that have been examined with these tools include trade-offs among setting aside areas for conservation (e.g., Natura2000 network) while at the same time expanding renewable energy platforms (wind farm development) and maintaining healthy, productive fisheries (VECTORS 2013).

\subsection{Strengths and Weaknesses of End-to-end models}

End-to-end models may include a great number of species, a high biological and functional variability and an increased number of potentially interacting components / features. A clear shortcoming is the large number of parameters that exist and their associated uncertainties (Pikitch et al., 2004). The uncertainties of other types of models (e.g. food web models) also exist within end-to-end models. For example, model estimates of end-to-end models (and most foodweb models) are sensitive to assumptions made on food web interactions such as the functional response of predators (Fulton et al., 2003). The data needed to allow one to choose between alternative parameter estimates in end-to-end models (and foodweb models in general) are often lacking (FAO, 2008). In addition, the spatiotemporal scales at which processes occur may differ by many orders of magnitude, whereas complexity may be increased due to the direct and indirect effects of anthropogenic impacts (i.e. fisheries) (Travers et al., 2007). Assessing the validity of estimates derived from end-to-end models is crucial to convince stakeholders of the relevance of such complex models to support the decision-making process.

Testing the validity of models incorporating human sectors and pressures is an active area of research. Within end-to-end models, three methods (perturbation analysis, global sensitivity analysis and the bounded parameterization) were proposed by Fulton (2010) for handling uncertainty and for assessing model sensitivity. The perturbation analysis includes the intentional perturbation (decrease, increase, or systematic change) of the different components of the ecosystem and the mapping of the flow of consequences to all other components (Fulton, 2010). The robustness of model outputs can be explored by means of advanced sensitivity analysis techniques (Lehuta et al. 2013b). Classification trees built from these simulations can be used to perform uncertainty analysis and assess the robustness of results to input parameter values (Gasche et al., 2013). The bounded parameterizations method considers the most pessimistic, 
middle and optimistic version for each of the major dimensions of the system (e.g. productivity and vulnerability, human impacts) (Fulton, 2010). Risk assessment for different management decisions can only be conducted by discussing the uncertainty in parameter values (estimation error) and/or model structure (process error).

The advancement of these more complex models is essential if one hopes to fully quantify and evaluate predictions of different ecosystem-based management strategies (Degnbol, 2002 and FAO, 2008). Different end-to-end models have been developed for different reasons. For example, Atlantis (Figure 8) offers a framework to assist in strategic management decisions (comparison of the 'relative' but not necessarily the 'absolute' changes in costs and trade-offs due to direct and indirect effects of different management actions). When building these types of models, the right level of complexity needs to be found in line with the level of process understanding and data availability (Fulton et al., 2003). The end-to-end models may seem an ideal tool to be used in ecosystem-based approaches and their use in management forecasts will increase after their performance is adequately tested and critical knowledge gaps are identified and filled (Rose et al., 2010).

\section{Discussion and Conclusions}

Multiple pressures such as climate change, eutrophication and pollution, biological resource harvesting, habitat alteration, and introduced/alien species are causing fundamental changes to marine ecosystems including altered productivities and distributions of living marine resources (Bax et al., 2003, FAO, 2007, Díaz and Rosenberg, 2008; Barange and Perry, 2009 and Rabalais et al., 2010). Furthermore, a variety of activities in shallow, coastal areas (e.g., dredging for shipping ports, trawling of fishing gear, aggregate extraction, windfarm construction, artificial reefs, aquaculture of finfish and shellfish) cause direct physical alteration of bottom habitats with deleterious (or beneficial) short- and potentially long-term consequences for resident biota (Lindeboom et al., 2011 and Canu et al., 2010). These pressures acting on the marine environment, when combined with land-based pressures, are causing a loss of global biodiversity and biological natural capital at an unprecedented rate in earth's history. It is paramount to develop tools that can project future changes and provide sufficient information to decision makers on how to best manage natural systems. 
Our brief review has highlighted the current state-of-the art in models used in the EU 'VECTORS' program and other key examples that help one detect patterns and key associations, formulate hypotheses on processes, test those processes and advance the capacity to understand and predict changes in the distribution and productivity of living marine resources. It is important to note that all modelling tools have strengths and weaknesses and that our separation of various approaches into different categories (statistical analyses, physiological-based biophysical models, full life cycle models, food-web models, and end-to-end models) was often imperfect and oversimplified. Clearly some modelling examples that we discussed bridge the gap across categories (see Figure 1).

It is a daunting and likely counterproductive task to review all of the different modelling tools that have been developed to assess changes in the distribution and productivity of living marine resources. One rapidly loses the "forest for the trees". Moreover, a number of reviews exists that discuss, in great detail, different model types such as IBMs of fish early life stages (Peck and Hufnagl, 2012), DEBs of juvenile and adult life stages of various organisms (Kooijman, 2010) and end-to-end models of marine systems (Travers et al., 2007 and Rose et al., 2010 \& 2015). Furthermore, reviews already exists comparing different modelling tools applied to specific research questions such as ecosystem-based fisheries management (Plagányi, 2007), the ability to project the impacts of ocean warming and acidification (Koenigstein et al., 2016), or the development of indicators of ecosystem health (Rombouts et al., 2013). For these reasons, we have chosen to briefly review broadly different categories of models in terms of their strengths and weaknesses and their ability to detect and project changes in the distribution and productivity of living marine resources. Our review includes statistical (SDMs, DBEMs), biophysical (IBM), food web (Size-spectrum, OSMOSE) and end-to-end (Atlantis) models that we have helped develop and apply as well as a few other models developed and applied by others (Table 1).

The models reviewed here have large differences in their design (from single species to food webs), the extents to which different mechanism are included (from physics, trophodynamics, to physiology), and their attributes. Model class attributes include, for example, whether or not a model has a common structure (facilitating comparisons across different applications) or diagnostic tools (examining model skill). We have applied a traffic light rating system based upon our (the authors') judgement. Common issues exist among most of the model categories 
including: 1) a lack of emphasis (thus far) on incorporating adaptive capacity of species to environmental change, and 2) building dynamic feedback loops between predators and their prey in coupled model systems as well as 3) including density dependence. In terms of examining multiple environmental pressures and their drivers, most models have the capacity and/or have been used to examine the interactions between climate and fishing but fewer applications (e.g. EwE, Atlantis) have included non-indigenous invasive species (either alone or as an interacting factor). We assume that the lack of application of models to address some interacting factors is, for the most part, due to a lack of data / measurements (e.g., diets and competitive interactions of novel species, tolerance and responses of biota to bouts of hypoxia, etc.). However, the potential clearly exists for coupled models (both physical and biological models) to examine the interaction between potential drivers such as overfishing, climate, invasive alien species, eutrophication, etc. (e.g. Metcalfe et al., 2015). Using more complex, end-to-end approaches, one can also examine the potential economic impacts of spatially-explicit ecological changes.

There is a growing consensus that flexible tools need to be created that capture information on how the previously mentioned interacting pressures and drivers affect key species and their food web interactions. To do this, process knowledge on how multiple factors interact to affect individuals, populations and food web dynamics is needed. Integrating physiological and ecological knowledge is critical if we hope to advance predictive capacity (Koenigstein et al., 2016). At each level of biological organization, gaps in knowledge exist that need to be filled to improve the predictive capacity of models. These gaps in knowledge include:

1) Individual-level: For many species, there is a general lack of knowledge on how abiotic factors interact to control their vital rates (survival, growth, feeding, reproduction). This makes it difficult to parameterize models that can provide robust projections of the cumulative impacts caused by, for example, warming, reduced dissolved oxygen concentrations, increased $\mathrm{CO}_{2}$ concentrations (hypercapnia) and decreased $\mathrm{pH}$. A mechanistic, cause-and-effect understanding of how key abiotic factors interact to affect vital rates (including optimal and suboptimal yet tolerable limits defining a species' fundamental niche) is needed (Pörtner and Peck, 2010; Koenigstein et al., 2016). Moreover, individuals pass through different life stages and each life stage may have a unique tolerance or sensitivity to environmental factors due to morphological, 
developmental and behavioural differences (Rijnsdorp et al., 2009; Petitgas et al., 2012b). Finally, abiotic factors may interact with biotic factors in unexpected ways to change the potential for growth, survival and reproduction. Physiological experiments can be performed to obtain these data, although the translation of this information from the laboratory to the field situation and, ultimately, into modeling may be challenging.

2) Population-level: Moving from projections of individual- to population-level responses to interacting stressors requires knowledge on additional, key processes. These processes include links between extrinsic and intrinsic properties of populations such as the propensity for density-dependent controls of habitat selection or productivity as discussed by Planque et al. (2011b) for marine fish populations. In terms of purely intrinsic attributes at the population level, the extent of phenotypic plasticity of key traits (such as development rate: Jackson et al., 2012) may alter the ability of different populations to adapt to environmental change (Chown et al., 2007). It will also be important to account for extrinsic differences among populations; different populations often persist in unique environmental settings that may be more or less resilient to physical and biological habitat perturbations. One can envision many examples including differences in the strength of connectivity between suitable habitats for subsequent life stages (e.g., geographic features), the presence or absence of predators and competitors, or diet breadth as affected by the availability of suitable prey species. Thus, species-level responses to habitat change caused by multiple, interacting stressors will likely differ among populations, suggesting caution when using a model to project changes in the distribution and productivity across the full geographical range of a species (as is routinely done in bioclimate modelling).

3) Ecosystem-level: One of the most intractable challenges is projecting changes in ecosystem structure and function that result from perturbations to the abundance and productivity of individual species, altered species composition (including novel species) and small- and large-scale changes in habitat characteristics. Ecosystem-level projections must account for changes in the strength of species interactions via bottom-up, top-down and intraguild processes. It is important to note that ecosystem-level effects will emerge from the aggregate response of individual species and that many of these responses may 
have a physiological-basis. In a recent example, Kempf et al. (2013) used habitat modelling to examine temporal changes in the distribution of 0-group cod and grey gurnard (Eutriglia gurnardus) at different spatial scales. Their results highlighted how physiological-based differences in preferred habitat characteristics control the strength of food web coupling that may ultimately limit the productivity of a species. An important, ongoing development which should produce more realistic dynamics within food web models is representing better dynamics at the base of food web models (e.g., remotely sensed time series data of phytoplankton within an Ecospace module of EwE (Steenbeek et al., 2013). Although two-way coupling between upper and lower trophic level models is currently offered in many end-to-end approaches (Travers et al., 2009), efforts to link existing lower and upper trophic level models are ongoing and emphasize the importance of correctly representing zooplankton dynamics (Daewel et al., 2014). Coupling models that include the effects of biophysical forcing on lower trophic levels (e.g., zooplankton) to upper trophic levels represented as a simple size spectrum (Blanchard et al., 2012) or by a complex suite of interacting species (Marzloff et al., 2009 and Travers et al., 2010) will ultimately lead to a better understanding of how the flow of energy through food webs can be disrupted or changed by coastal habitat loss/degradation, climate change, fishing and other interacting drivers.

In general, the predictive power of models attempting to explain the causes and the consequences of changes in the distribution and productivity of species is seriously hampered by additional factors. First, analytical models cannot include all of an ecosystem's components and abiotic factors, thus, our emphasis is normally to include a few taxa or taxonomic / functional groups or resources and the remaining ecosystem components are either simply ignored or oversimplified. This is not necessarily a drawback, models should be "fit for purpose" or designed to answer the questions being posed by investigators. Second, a multitude of anthropogenic drivers interact to simultaneously cause state changes in environments and it is difficult to disentangle cause-andeffect relationships. However, models are often the only tool that can be used to test the potential strength of interactions and/or help disentangle dominant processes underlying patterns in field data (e.g. Guénette et al., 2006 and Hufnagl et al., 2015). Moreover, we are limited in our ability to conduct experiments at appropriate (large) scales. Patterns observed and processes inferred 
from the result of small-scale experiments may differ from those at larger (field) scales (Gaston and Blackburn, 1999).

When building models that attempt to project changes in the spatial and temporal distribution of living marine resources there needs to be recognition that error and variability exists at every step of the process from uncertain field measurements / observations, to conceptual, structural, and predictive model uncertainty (Planque et al., 2011a) and that the validity of any model depends on the criteria used to assess it (Allen et al., 2007). The challenges of dealing with uncertainty in model projections, particularly when model outputs are needed to supply advice to managers of natural resources, are being voiced across many different natural systems including climatevegetation models and forest management (Littell et al., 2010). A recognition of what models can and cannot do is critical - embracing the idea that every model has structural uncertainty (design limitations causing bias and error) as well as parameter uncertainty (causing uncertainty in model output). Several authors have promoted the use of specific metrics that reflect various aspects of model skill (correlation, efficiency, accuracy) and have provided more quantitative elements for model evaluation (Jolliff et al., 2009). Sensitivity analyses are also efficient, mathematical tools to use to assess the validity of the estimates obtained from complex models (Maunder et al., 2006, Lehuta et al., 2010 \& 2013a and Peck and Hufnagl, 2012). More complex, end-to-end approaches include different techniques to examine model sensitivity (Fulton, 2010) although "pattern matching" is often used as a measure of model performance (i.e., simulated and observed trends share the same patterns). Standardized reporting of model sensitivity, precision and accuracy is needed. It is particularly important to effectively communicate the uncertainties associated with estimates obtained by coupling separate models or from complex, end-to-end models. The recognition and assessment of cumulative error and uncertainties from coupled models are intrinsic in the formulation of models in the Bayesian framework, but it is far from the case for most models examined here, for which parallel efforts are needed to increase both the capacity of models (such as complex, end-to-end approaches) and the collection of data required to parameterize models (and that can be used to challenge their predictions and scenarios).

It is clear that different models are able to capture different processes at different scales that may interact to cause changes in the distribution and productivity of living marine resources. An issue that often confronts modelers is the ability to capture processes acting at the appropriate scales 
and moving from small, fine scales to large, coarse scales. On the one hand, downscaling has been discussed with respect to the need to dynamically represent physical and biogeochemical output from Global Climate Models or Earth System Models from coarse to finer scales to resolve climate-driven variability in key habitat features such as mesoscale (20 to $200 \mathrm{~km}$ ) fronts and eddies (Stock et al., 2011). On the other hand, in some cases it will be important (and challenging) to upscale processes occurring at fine scales (several meters to $\mathrm{kms}$, such as predator-prey hot spots (Temming et al., 2007) and/or aggregation of particles within thin layers and other small-scale structures (Möller et al., 2012). If one has the ambition to adequately capture ecosystem-dynamics at larger scales, it is also important to note the limitations of historical time series data. These limitations include having data sets of adequate length to capture inter-decadal cycles (such as the PDO or AMO) affecting ecosystem dynamics such as regime shifts (Hare \& Mantua 2000) and/or that local phenomena may result from physical and/or biological processes occurring well upstream and that are not adequately captured/ modeled by simple boundary assumptions. An example of the importance of downstream impacts was provided by Taylor et al. (2002) who found strong links between a weak climate signal spread across various meteorological variables associated with the northern wall of the Gulf Stream and field data on the planktonic ecosystem of the NW European Shelf Seas (illustrating basin-scale connections). A biogeochemical and LTL model of the marine ecosystem (ERSEM, Allen et al., 2001) was able to reproduce this link when the model was run at the appropriate (large) scale. The example highlights how ecosystems may respond to seemingly subtle or weak climate signals rather than merely to local changes in major factors such as water temperature.

One suggestion to improve modelling capacity is to build modular frameworks allowing different models to be coupled (the assemblage model approach recommended by various authors (Planque et al., 2011b, Robinson et al., 2011 and Kempf et al., 2013)). Coupling existing models allows different, important mechanisms to be included such as transport of early life stages (Daewel et al., 2011 and Peck and Hufnagl, 2012), physiological tolerance and habitat niches (Sykes et al., 1996; Pearson and Dawson, 2003 and Cucco et al., 2012) and trophodynamic processes (Kempf et al., 2013). One advantage of this approach is a lower complexity (compared to full end-to-end models). A main drawback is when coupled models lack dynamic feed-back loops between components leading to a loss in realism. In one example of coupled modelling, a full life-cycle model for fish (Rochette et al., 2013) was coupled to the 3-D biogeochemical 
model ECOMARS (Huret et al., 2013) and to the spatially-explicit, multi-species, multi-fisheries dynamics model ISIS-Fish (Mahévas and Pelletier, 2004 and Pelletier et al., 2009). In that case, the coupled model approach, despite the lack of dynamic feedback, allowed management strategies (e.g., Total Allowable Catches, Marine Protected Areas) to be examined in terms of their effectiveness to conserve flatfish and benthic taxa in light of the cumulative impacts of fishing and aggregate extraction activities in coastal ecosystems (Gasche et al., 2013)

Importantly, in some cases, existing tools will not be sufficient to capture all relevant processes and new tools will be required. A major issue confronting scientists charged with making predictions of future distribution and productivity is the ability of species to adapt to altered environmental conditions. Trait-based approaches are ideally suited to tackle that question. Furthermore, economics cannot be overlooked if models hope to inform management. Spatiallyexplicit models incorporating one or more economic sectors such as ISIS Fish (Mahévas and Pelletier, 2004), FishRent (Simons et al., 2015) or Atlantis (Fulton et al., 2011 and Griffith et al., 2012) will then be able to use scenarios to estimate how various economic sectors (the drivers behind various pressures) will likely impact the system and to evaluate the costs and trade-offs to various management options. Finally, developing and employing different types of models to examine the same areas, species and questions in an ensemble-like manner (see Gårdmark et al., 2013) will not only allow assumptions made in more complex models to be more easily tested but will also allow a weight-of-evidence approach to be developed that will hopefully increase confidence in model projections of changes in species distribution and productivity.

\section{Acknowledgements}

The research leading to these results has received funding from the European Union's Seventh Framework Programme for research, technological development and demonstration (FP7/20072013) within the Ocean of Tomorrow call under Grant Agreement No.266445 for the project Vectors of Change in Oceans and Seas Marine Life, Impact on Economic Sectors (VECTORS). This work is also a contribution to the EU Cost Action FA1004 "Conservation Physiology". PS acknowledges support from the UK Natural Environment Research Council and Department for Environment, Food and Rural Affairs [grant number NE/L003279/1, Marine Ecosystems Research Programme. The authors wish to thank Drs. Jason Link, Elizabeth Fulton and Øivind 
Fiksen as well as an anonymous reviewer for their helpful comments on an earlier version of this manuscript. This work also benefitted from discussions among members of the ICES Working Group on Integrated Physical-biological and Ecosystem Modelling (WGIPEM) and the ICESPICES Strategic Initiative on Climate Change Impacts on Marine Ecosystems (SICCME). 
References

Allen, J.I., Blackford, J.C., Holt, J., Proctor, R., Ashworth, M., and Siddorn, J., 2001. A highly spatially resolved ecosystem model for the North West European Continental Shelf. Sarsia 86, 423-440.

Allen, J.I., Somerfield, P.J., and Gilbert, F.J., 2007. Quantifying uncertainty in high-resolution coupled hydrodynamic-ecosystem models. J. Mar. Systems 64, 3-14.

Altieri, A.H., 2008. Dead zones enhance key fisheries species by providing predation refuge. Ecology 89, 2808-2818.

Anderson, B.J., Akçakaya, H.R., Araújo, M.B., Fordham, D.A., Martinez-Meyer, E., and Brook, B.W., 2009. Dynamics of range margins for metapopulations under climate change. Proc. Royal Soc. B. 276, 1415-1420.

Barange, M., and Perry, R.I., 2009. Physical and ecological impacts of climate change relevant to marine and inland capture fisheries and aquaculture. In Climate Change Implications for Fisheries and Aquaculture. Overview of Current Scientific Knowledge (Eds. Cochrane, K., De Young, C., Soto, D., Bahri, T.), pp. 7-106. FAO Fisheries.

Bax, N., Williamson, A., Aguero, Gonzalez, E., and Geeves, W., 2003. Marine invasive alien species: a threat to global biodiversity. Mar. Policy 27, 313-323.

Beare, D.J., Burns, F., Greig, A., Jones, E.G., Peach, K., Kienzle, M., McKenzie, E., and Reid, D.G. 2004. Longterm increases in prevalence of North Sea fishes having southern biogeographic affinities. Mar. Ecol. Prog. Ser. 284, 269-278.

Beaugrand, G., and Reid, P.C., 2003. Long-term changes in phytoplankton, zooplankton and salmon related to climate. Global Change Biol. 9(6), 801-817.

Beaugrand, G., Brander, K.M., Lindley, J.A., Souissi, S., and Reid, P.C., 2003. Plankton effect on cod recruitment in the North Sea. Nature, 426: 661-664.

Blanchard, J. L., Jennings, S., Holmes, R., Harle, J., Merino, G., Allen, J., and Barange, M., 2012. Potential consequences of climate change for primary production and fish production in large marine ecosystems. Philosophical Trans. Royal Soc. B: Biological Sciences, 367(1605), 2979-2989.

Blanchard, J.L., Law, R., Castle, M.D., and Jennings, S. 2011. Coupled energy pathways and the resilience of size-structured food webs. Theoretical Ecology, 4 (3): 1-12.

Brodeur, R.D., Ruzicka, J.J., and Steele, J.H. 2011. Investigating alternate trophic pathways through gelatinous zooplankton and planktivorous fishes in an upwelling ecosystem using end-to-end models, pp. 57-63, in K. Omori, X. Guo, N. Yoshie, N. Fujii, I. C. Handoh, A. Isobe and S. Tanabe, Eds., Interdisciplinary Studies on Environmental ChemistryMarine Environmental Modeling \& Analysis, TERRAPUB.

Brown, J.H., Gillooly, J.F., Allen, A.P., Savage, V.M., and West, G.B., 2004. Toward a metabolic theory of ecology. Ecology, 85: 1771-1789.

Canu, D.M, Solidoro, C., Cossarini, G., and Giorgi, F. 2010. Effect of global change on bivalve rearing activity and the need for adaptive management. Climate Research, 42: 13-26. 
Cheung, W.W.L., Dunne, J., Sarmiento, J.L., and Pauly, D., 2011. Integrating ecophysiology and plankton dynamics into projected maximum fisheries catch potential under climate change in the Northeast Atlantic. ICES Journal of Marine Science, 68: 1008-1018.

Cheung, W.W.L., Lam, V.W.Y., Sarmiento, J.L., Kearney, K., Watson, R., and Pauly, D., 2009. Projecting global marine biodiversity impacts under climate change scenarios. Fish Fish. $10,235-251$.

Chown, S.L., Slabber, S.,McGeoch, M.A., Janion, C., Leinaas, H.P., 2007. Phenotypic plasticity mediates climate change responses among invasive and indigenous arthropods. Proc. Royal Acad. Sci. B 274, 2531-2537.

Christensen, V., Walters, C.J., 2004. Ecopath with Ecosim: methods, capabilities and limitations. Ecol. Model. 172, 109-139.

Christensen, V., Coll, M., Steenbeek, J., Buszowski, J., Chagaris, D., and Walters, C.J. 2014. Representing variable habitat quality in a spatial food web model. Ecosystems 17, 13971412.

Clark, R.A., Frid, C.L., 2001. Long-term changes in the North Sea ecosystem. Environ. Reviews, 9, 131-187.

Cooke, S.J., Hinch, S.G., Donaldson, M.R., Clark, T.D., Eliason, E.J., Crossin, G.T., Raby, G.D., Jeffries, K.M., Lapointe, M., Miller, K., Patterson, D.A., Farrell, A.P. 2012. Conservation physiology in practice: how physiological knowledge has improved our ability to sustainably manage Pacific salmon during up-river migration. Philosophical Transactions of the Royal Society, B 367, 1757-1769.

Cucco, A., Sinerchia, M., Lefrançois, C., Magni, P., Ghezzo, M., Georg Umgiesser, G., Angelo Perilli, A., Domenici, P., 2012. A metabolic scope based model of fish response to environmental changes. Ecol. Model. 237/238, 132-141.

Daewel, U., Peck, M.A., Schrum, C., 2011. Life history strategy and impacts of environmental variability on early life stages of two marine fishes in the North Sea: an individual-based modelling approach. Can. J. Fish. Aquat. Sci. 68, 426-443.

Daewel, U., Peck, M.A., Schrum, C., St. John, M.A., 2008. How best to include the effects of climate-driven forcing on prey fields in larval fish individual-based models. J. Plankton Res. 30, 1-5.

Daewel, U., Sætre Hjøllo, S., Huret, M., Ji, R., Maar, M., Niiranen, S., Travers-Trolet, M., Peck, M.A., van de Wolfshaar, K.E., 2014. Predation control off zooplankton dynamics: a review on of observations and models. ICES J. Mar. Sci. 71, 254-271.

Degnbol, P., 2002. The ecosystem approach and fisheries management institutions: the noble art of addressing complexity and uncertainty with all onboard and on a budget. IIFET 2002 paper. no 171.

Díaz, R.J., Rosenberg, R., 2008. Spreading dead zones and consequences for marine ecosystems. Science 321, 926-929.

Doney, S.C., 2010. The growing human footprint on coastal and open-ocean biogeochemistry. $328,1512-1516$.

Dulvy, N.K., Rogers, S.I., Jennings,S ., Stetzenmiller, V., Dye, S.R., Skjoldal, H.R., 2008. 
Climate change and deepening of the North Sea fish assemblage: a biotic indicator of warming seas. J. Appl. Ecol. 45,1029-1039.

Durbin, A.G., Durbin, E.G., 1998. Effects of menhaden predation on plankton populations in Narragansett Bay, Rhode Island. Estuaries 21, 449-465.

FAO 2007. The State of World Fisheries and Aquaculture 2006, FAO, Fisheries and Aquaculture Department.

FAO 2008: Fisheries management. 2. The ecosystem approach to fisheries. 2.1 Best practices in ecosystem modelling for informing an ecosystem approach to fisheries. FAO Fisheries Technical Guidelines for Responsible Fisheries. No. 4, Suppl. 2, Add. 1.

Fernandes, J.A., Cheung, W.W.L., Jennings, S., Butenschön. M., de Mora, L., Frölicher, T.L., Barange, M., Grant, A., 2013a. Modelling the effects of climate change on the distribution and production of marine fishes: accounting for trophic interactions in a dynamic bioclimate envelope model. Global Change Biol. 19(8), 2596-2607.

Fernandes J.A., Lozano J.A., Inza I., Irigoien X., Rodríguez J.D., Pérez A., 2013b. Supervised pre-processing approaches in multiple class-variables classification for fish recruitment forecasting. Environmental Modelling and Software 40, 245-254.

Fielding, A.H., Bell, J.F., 1997. A review of methods for the assessment of prediction errors in conservation presence/absence models. Environmental Conservation, 24 (1): 38-49.

Frank, K. T., Petrie, B., Choi, J. S., Leggett, W.C., 2005. Trophic cascades in a formerly coddominated ecosystem. Science 308, 1621-1623.

Freitas, V., Cardoso, J.F.M.F., Lika, K., Peck, M.A., Campos, J., Kooijman, S.A.L.M., van der Veer, H.W., 2011. Temperature tolerance and energetics: a dynamic energy budget-based comparison of North Atlantic marine species. Phil. Trans. Royal Soc. B 365, 3553-3565.

Fry, F.E.J. 1957. The aquatic respiration of fish. Pages 1-63 in M. E. Brown, editor. The physiology of fishes, volume 1. Academic Press, New York, USA.

Fry, F.E.J. 1971. The effect of environmental factors on the physiology of fish. In, Fish Physiology, Vol. 6. W.S. Hoar, D.J. Randall, J.R. Brett, (eds)., Academic Press, New York, pp 1-98.

Fulton, E.A., 2010. Approaches to end-to-end ecosystem models. J. Mar. Systems 81, 171-183.

Fulton, E.A. 2011. Interesting times: winners, losers, and system shifts under climate change around Australia. ICES Journal of Marine Science, 68(6): 1329-1342.

Fulton, E.A., Link, J.S, Kaplan I.C., Savina-Rolland, M., Johnson, P., Ainsworth, C., Horne, P., Gorton, R., Gamble, R.J., Smith, A.D.M., and Smith, D.C. 2011. Lessons in modelling and management of marine ecosystems: the Atlantis experience. Progress in Oceanography, 12: 171-188.

Fulton, E.A., Smith, A.D.M., and Johnson, C.R. 2003. Effect of complexity on marine ecosystem models. Marine Ecology Progress Series, 253: 1-16.

Gårdmark A, Lindegren M, Neuenfeldt S, Blenckner T, Heikinheimo, O., Müller-Karulis, B., Niiranen, S., Tomczak, M.T., Aro, E., Wilström, A. \& Möllmann, C. 2013 Biological 
ensemble modelling to evaluate potential futures of living marine resources. Ecological Applications 23, 742-754.

Galil, B.S., Marchini, A., Occhipinti-Ambrogi, A., Minchin, D., Narščrius, A., Ojaveer, H., Olenin, S. 2014. International arrivals: widespread bioinvasions in European Seas. Ethology Ecology and 1-20 http://dx.doi.org/10.1080/03949370.2014.897651.Garcia, S. M., Zerbi, A., Aliaume, C., Do Chi, T. \& Lasserre, G., 2003 The ecosystem approach to fisheries. Issues, terminology, principles, institutional foundations, implementation and outlook. FAO Fisheries Technical Paper. 443.

Gasche, L., Mahévas, S., and Marchal, P., 2013. Supporting fisheries management by means of complex models: Can we point out isles of robustness in a sea of uncertainty? PLoS ONE 8(10): e77566. doi:10.1371/journal.pone.0077566

Gaston, K.J., and Blackburn, T.M., 1999. A critique for macroecology. Oikos, 84(3): 353-368.

Griffith, G. P., Fulton, E.A., Gorton, R., and Richardson, A. 2012. Predicting Interactions among fishing, ocean warming, and ocean acidification in a marine system with whole-ecosystem models. Conservation Biology, 26(6): 1145-1152.

Guénette, S., Heymans, J.J., Christensen, V., Trites, A.W., 2006. Ecosystem models show combined effects of fishing, predation, competition, and ocean productivity on Steller sea lions (Eumetopias jubatus) in Alaska. Canadian Journal of Fisheries and Aquatic Sciences. 63, 2495-2517.

Hanson, P., Johnson, T., Kitchell, J., and Schindler, D.E. 1997. Fish Bioenergetics 3.0. University of Wisconsin Sea Grant Institute, Report WISCU-T-97-001, Madison.

Hare, S. R. and Mantua, N. J. 2000. Empirical evidene for North Pacific regime shifts in 1977 and 1989., Progress in Oceanography, 47: 103-145.

Hengl, T. 2009. A Practical Guide to Geostatistical Mapping. Office for Official Publications of the European Communities, Luxembourg.

Herborg, L.M., Jerde, C.J., Lodge, D.M., Ruiz, G.M., and MacIsaac, H.J. 2007. Predicting invasion risk using measures of introduction effort and environmental niche model. Ecological Applications, 17: 663-674.

Hiddink, J.G,, Burrows, M.T., and Molinos, J.G. 2015. Temperature tracking by North Sea benthic invertebrates in response to climate change. Global Change Biology, 21: 117129.

Hobbs, R. J., Higgs, E., and Harris, J.A. 2009. Novel ecosystems: implications for conservation and restoration. Trends in Ecology and Evolution, 24: 599-605.

Hufnagl, M., and Peck, M.A. 2011. Physiological-based modelling of larval Atlantic herring (Clupea harengus) foraging and growth: Insights on climate-driven life history scheduling. ICES Journal of Marine Science, 68(6):1170-1188.

Hufnagl, M., Peck, M.A., Nash, R.D.M., Dickey-Collas, M. 2015. Unravelling the Gordian knot! Key processes impacting overwintering larval survival and growth: A North Sea herring case study. Progress in Oceanography 138: 486 - 503. 
Hulme, P.E., Roy, D.B., Cunha, T., and Larsson, T.-B. 2008. A pan-European inventory of alien species: rationale, implementation and implications for managing biological invasions. In DAISIE (eds.) The Handbook of European Alien Species. Springer, Dordrecht.

Hunt, G.L., Stabeno, P., Walters, G., Sinclair, E., Brodeur, R.D., Napp, J.M., and Bond, N.A. 2002. Climate change and control of the southeastern Bering Sea pelagic ecosystem. Deep-Sea Res. II, 49: 5821-5853.

Huntley, B., Barnard, P., Altwegg, R., Chambers, L., Coetzee, B.W.T., Gibson, L., Hockey, P.A.R., Hole, D.G., Midgley, G.F., Underhill, L.G., and Willis, S.G. 2010. Beyond bioclimatic envelopes: dynamic species' range and abundance modelling in the context of climate change. Ecography, 33: 621-626.

Huret, M., Sourisseau, M., Petitgas, P., Struski, C., Leger, F., and Lazure, P. 2013. A multidecadal hindcast of a physical-biogeochemical model and derived oceanographic indices in the Bay of Biscay. Journal of Marine Systems, 109-110: S77-94.

Huse, G., Ellingsen, I. 2008. Capelin migrations and climate change - a modelling analysis. Climate Change, 87: 177-197.

Hyder, K., Rossberg, A.G., Allen, J.I., Austen, M.C., Barciela, R.M., Bannister, H.J., Blackwell, P.G., Blanchard, J.L., Burrows, M.T., Defriez, E., Dorrington, T., Edwards, K.P., GarciaCarreras, B., Heath, M.R., Hembury, D.J., Heymans, J.J., Holt, J., Houle, J.E., Jennings, S., Mackinson, S., Malcolm, S.L., McPike, R., Mee, L., Mills, D.K., Montgomery, C., Pearson, D., Pinnegar, J.K., Pollicino, M., Popova, E.E., Rae, L., Rogers, S.I., Speirs, D., Spence, M.A., Thorpe, R., Turner, R.K., van der Molen, J., Yool, A., Paterson, D.M. 2015. Making modelling count - increasing the contribution of shelf-seas community and ecosystem models to policy development and management. Marine Policy, 61: 291-302.

IPCC, 2013. Climate Change 2013: The Physical Science Basis. Contribution of Working Group I to the Fifth Assessment Report of the Intergovernmental Panel on Climate Change. Stocker, T.F., D. Qin, D., Plattner, G.-K.m et al. (eds.). Cambridge University Press, Cambridge, United Kingdom, 1535 pp.

Jackson, D.J., Degnan, S.M., and Degnan, B.M. 2012. Variation in rates of early development in Haliotis asinina generate competent larvae of different ages. Frontiers in Zoology, 9.2. http://www.frontiersinzoology.com/content/9/1/2

Jennings, S., and Brander, K. 2010. Predicting the effects of climate change on marine communities and the consequences for fisheries. Journal of Marine Systems, 79: 418-426.

Jennings, S., Mélin, F., Blanchard, J. L., Forster, R. M., Dulvy, N. K. and Wilson, R. W. 2008 Global-scale predictions of community and ecosystem properties from simple ecological theory. Proceedings of the Royal Society, B, 275: 1375-1383.

Jolliff, J.K., Kindle, J.C., Shulman, I., Penta, B., Friedrichs, M.A.M., Helber, R.et al., 2009. Summary diagrams for coupled hydrodynamic-ecosystem model skill assessment. Journal of Marine Systems, 76: 64-82.

Jones, M.C., and Cheung, W.W.L. 2014. Multi-model ensemble projections of climate change effects on global marine biodiversity. ICES Journal of Marine Science doi: 10.1093/icesjms/fsu172. 
Jones, M.C., Dye, S.R., Fernandes, J.A., Frölicher, T.L., Pinnegar, J.K., Warren, R., and Cheung, W.W.L. 2013. Predicting the impact of climate change on threatened species in UK waters. PLoS ONE 8(1): e54216. doi:10.1371/journal.pone.0054216.

Jones, M.C., Dye, S.R., Pinnegar, J.K., Warren, R., and Cheung, W.W.L. 2012. Modelling commercial fish distributions: Prediction and assessment using different approaches. Ecological Modelling, 225: 133-145.

Jørgensen, C., Peck, M.A., Antognarelli, F., Azzurro, E., Burrows, M.T., Cheung, W.W.L., Cucco, A., Holt R.E., Huebert, K.B., Marras, S., McKenzie, D., Julian Metcalfe, J., PerezRuzafa, A., Sinerchia, M., Steffensen J.F., Teal, L.R., and Domenici, P. 2012. Conservation physiology of marine fish: Advancing the predictive capacity of models. Biology Letters doi:10.1098/rsbl.2012.0609.

Kaplan, I.C., Gray, I.A., and Levin, P.S. 2012. Cumulative impacts of fisheries in the California Current. Fish and Fisheries DOI: 10.1111/j.1467-2979.2012.00484.x

Kempf, A., Stelzenmüller, V., Akimova, A., and Floeter, J. 2013. Spatial assessment of predatorprey relationships in the North Sea: the influence of abiotic habitat properties on the spatial overlap between 0-group cod and grey gurnard. Fisheries Oceanography, 22(3): 174-192.

Kerr, S.R., and Dickie, L.M. 2001. The Biomass Spectrum. A Predator-Prey Theory of Aquatic Production. University Press, 344 pp.

Kishi, M.J., Ito, S.-i., Megrey, B.A., Rose, K.A., and Werner, F.E. 2011. A review of the NEMURO and NEMURO.FISH models and their application to marine ecosystem investigations. Journal of Oceanography, 67:3-16.

Koenigstein, S., Mark, F.C., Gößling-Reisemann, S., Reuter, H., and Poertner, H.-O. 2016. Modelling climate change impacts on marine fish populations: process-based integration of ocean warming, acidification and other environmental drivers. Fish and Fisheries DOI: 10.1111/faf.12155

Kooijman, S.A.L.M. 2010. Dynamic energy budget theory for metabolic organisation, Vol. Cambridge University Press, Cambridge.

Kraus, G., Tomkiewicz, J., and Köster, F.W. 2002. Egg production of Baltic cod (Gadus morhua) in relation to variable sex ratio, maturity, and fecundity. Canadian Journal of Fisheries and Aquatic Science, 59: 1908-1920.

Kühn, W., Peck, M.A., Hinrichsen, H.-H., Daewel, U., Moll, A., Stegert, C. and Tamm, S. 2008. Defining habitats suitable for larval fish in the German Bight (southern North Sea): An IBM approach using spatially and temporally resolved, size-structured prey fields. Journal of Marine Systems, 74: 329-342.

Lam, V.W., Cheung, W.W.L., Swartz, W., and Sumaila, U.R. 2012. Climate change impacts on fisheries in West Africa: implications for economic, food and nutritional security. African Journal of Marine Science, 34 (1): 103-117.

Lehodey, P., Senina I., Murtugudde, R. 2008. A spatial ecosystem and populations dynamics model (SEAPODYM) - Modeling of tuna and tuna-like populations. Progress in Oceanography 78, 304-318. 
Lehuta, S., Mahévas, S., Petitgas, P., and Pelletier, D. 2010. Combining sensitivity and uncertainty analysis to evaluate the impact of management measures with ISIS-Fish: marine protected areas for the Bay of Biscay anchovy (Engraulis encrasicolus) fishery. ICES Journal of Marine Science, 67: 1063-1075.

Lehuta, S., Mahévas, S., Petitgas, P., and LeFloch, P. 2013a. A simulation-based approach to assess sensitivity and robustness of fisheries management indicators for the pelagic fishery in the Bay of Biscay. Canadian Journal of Fisheries and Aquatic Science, 70: 2013-0066.

Lehuta, S., Petitgas, P., Mahevas, S.,Huret, M.,Vermard, Y.,Uriarte, A., and Record, N.R. 2013b. Selection and validation of a complex fishery model using an uncertainty hierarchy. Fisheries Research, 143: 57-66.

Libralato, S., Coll, M., Tempesta, M., Santojanni, A., Spoto, M., Palomera, I., Arneri, E., and Solidoro, C. 2012. Food-web traits of protected and exploited areas of the Adriatic Sea Biological Conservation, 143: 2182-2194.

Lindeboom, H.J., Kouwenhoven, H.J., Bergman M.J.N., Bouma, S., Brasseur, S, Daan, R., Fijn, R.C., de Haan, D., Dirksen, S., van Hal R., Hille Ris Lambers, R., terHofstede, R., Krijgsveld, K.L., Leopold, M., and Scheidat, M. 2011. Short-term ecological effects of an offshore wind farm in the Dutch coastal zone; a compilation. Environmental Research Letters, 6: 035101, doi:10.1088/1748-9326/6/3/03510.

Littell, J.S., O`Niel, E.E., McKenzie, D., Hicke, J.A. Lutz, J.A., Norheim, R.A., and Elsner, M.M. 2010. Forest ecosystems, disturbance, and climatic change in Washington State, USA. Climatic Change, 102: 129 -158.Llope, M., Licandro, P., Chan, K-S., and Stenseth, N.C. 2012. Spatial variability of the plankton trophic interaction in the North Sea: a new feature after the early 1970s. Global Change Biology, 18(1): 106-117.

Luisetti, T., Turner, R.K., Bateman, I.J., Morse-Jones, S., Adams, C., and Fonseca, L. 2011. Coastal and marine ecosystem services valuation for policy and management: Managed realignment case studies in England. Ocean and Coastal Management, 54: 212-224.

Mackinson, S., Daskalov, G., Heymans, J.J., Neira, S., Arancibia, H., Zetina-Rejón, M., Jiang, H., Cheng, H.Q., Coll, M., and Arreguin-Sanchez, F. 2009. Which forcing factors fit? Using ecosystem models to investigate the relative influence of fishing and changes in primary productivity on the dynamics of marine ecosystems. Ecological Modelling, 220: 2972-2987.

Mahévas, S., and Pelletier, D. 2004. ISIS-Fish, a generic and spatially explicit simulation tool for evaluating the impact of management measures on fisheries dynamics. Ecological Modelling, 171: 65-84.

Marshall, C.T.,Yaragina, B., Adlandsvik, A., and Dolgov, A.V. 2000. Reconstructing the stockrecruit relationship for North east Arctic cod using a bioenergetic index of reproductive potential. Canadian Journal of Fisheries and Aquatic Science, 57: 1-10.

Marzloff, M., Shin Y.-J., Tam J., Travers, M., and Bertrand A. 2009. Trophic structure of the Peruvian marine ecosystem in 2000-2006: Insights on the effects of management scenarios for the hake fishery using the IBM trophic model Osmose. Journal of Marine Systems, 75(1-2): 290-304. 
Maunder, M. N., Harley, S. J., and Hampton, J. 2006. Including parameter uncertainty in forward projections of computationally intensive statistical dynamic models. ICES Journal of Marine Science, 63: 969-979.

Merino, G., Barange, M., and Mullon, C. 2010. Climate variability and change scenarios for a marine commodity: Modelling small pelagic fish, fisheries and fishmeal in a globalized market. Journal of Marine Systems, 81: 196-205.

Merino, G., Barange, M., Blanchard, J.L., Harle, J., Holmes, R., Allen, I., Allison, E.H., Badjeck, M.C., Dulvy, N.K., Holt, J., Jennings, S., Mullon, C., and Rodwell, L.D. 2012. Can marine fisheries and aquaculture meet fish demand from a growing human population in a changing climate? Global Environmental Change, 22(4): 795-806.

Metcalfe, J.D., Le Quesne, W.J.F., Cheung, W.W.L., and Righton, D.A. 2012. Conservation physiology for applied management of marine fish: perspectives on the role and value of telemetry. Philosophical Transactions of the Royal Society B, 367: 1746-1756.

Metcalfe, K., Vaz, S., Engelhard, G. H., Villanueva, M. C., Smith, R. J., and Mackinson, S. 2015. Evaluating conservation and fisheries management strategies by linking spatial prioritization software and ecosystem and fisheries modelling tools, Journal of Applied Ecology. 52: 665-674.

Milly, P.C.D., J. Betancourt, M. Falkenmark, R.M. Hirsch, Z.W. Kundzewicz, D.P. Lettenmaier, and Stouffer, R.J. 2008. Stationarity is dead: Whither water management? Science, 319: 573-574.

Möller, K.O., St John, M., Temming, A., Floeter, J., Sell, A.F., Herrmann, J.P., and Möllmann, C. 2012. Marine snow, zooplankton and thin layers: indications of a trophic link from small-scale sampling with the Video Plankton Recorder. Marine Ecology Progress Series $468,57-69$.

Morzari-Luna, H. N., Aninsworth, C., Kaplin, I., Levin, P., and Fulton, E.A. 2012. Exploring trade-offs between fisheries and conservation of the Baquita porpoise (Phocoena sinus) using an Atlantis ecosystem model. PLoS ONE.7(8): e42917. doi:10.1371/journal.pone.0042917.

Mueter, F.J., Ladd, C., Palmer, M.C., and Norcross, B.L. 2006. Bottom-up and top-down controls of walleye pollock (Theragra chalcogramma) on the Eastern Bering Sea shelf. Progress in Oceanography, 68: 152-183.

Nicolas, D., Rochette, S., Llope, M., and Licandro, P. 2014. Spatio-temporal variability of the North Sea cod recruitment in relation to temperature and zooplankton. PLoS One 9(2):e88447 doi:10.1371/journal.pone.0088447.

Nisbet, R.M., Jusup, M., Klanjscek, T., and Pecquerie, L. 2012. Integrating dynamic energy budget (DEB) theory with traditional bioenergetic models. The Journal of Experimental Biology, 215: 892-902.

O’Connor, M.I., Bruno, J.F., Gaines, S.D., Halpern, B.S., Lester, S.E., Kinlan, B.P., and Weiss, J.M. 2007 Temperature control of larval dispersal and the implications for marine ecology, evolution, and conservation. Proceedings of the National Academy of Sciences of the United States of America 104, 1266-1271. 
Parent, E., and Rivot, E. 2012. Introduction to Hierarchical Bayesian Modeling for Ecological Data. Chapman \& Hall/CRC, Col. Applied Environmental Statistics, 427 pp.

Pearce, J., and Ferrier, S. 2000. Evaluating the predictive performance of habitat models developed using logistic regression. Ecological Modelling 133, 225-245.

Pearson, R.G., and Dawson, T.P. 2003. Predicting the impacts of climate change on the distribution of species: are bioclimate envelope models useful? Global Ecology and Biogeography 12, 361-371.

Peck, M.A., and Hufnagl, M. 2012. Can IBMs explain why most larvae die in the sea? Model scenarios and sensitivity analyses reveal research needs. Journal of Marine Systems 93, 77-93.

Peck, M.A., Reglero, P., Takahashi, M., and Catalán, I.A. 2013. Life cycle ecophysiology of small pelagic fish and climate-driven changes in populations. Progress in Oceanography $116,220-245$.

Pelletier, D., Mahévas, S., Drouineau, H., Vermard, Y., Thebaud, O., Guyader,O. \& Poussin, B. 2009. Evaluation of the bioeconomic sustainability of multi-species multi-fleet fisheries under a wide range of policy options using ISIS-Fish. Ecological Modelling 220 (7): pp. 1013-1033.

Perry, A.L., Low, P.J., Ellis, J.R., and Reynolds, J.D. 2005. Climate change and distribution shifts in marine fishes. Science, 308: 1912-1915.

Perry, R.I., Cury, P., Brander, K., Jennings, S., Möllmann, C., and Planque, B. 2010. Sensitivity of marine systems to climate and fishing: Concepts, issues and management responses. Journal of Marine Systems, 79: 427-435.

Petitgas, P., Alheit, J., Peck, M.A., Raab, K., Irigoien, X., Huret, M., van der Kooij, J., Pohlmann, T., Wagner, C., Zarraonaindia, I., and Dickey-Collas, M. 2012a. Anchovy population expansion in the North Sea. Marine Ecology Progress Series 444, 1-13.

Petitgas, P., Rijnsdorp, A.D., Dickey-Collas, M., Engelhard, G.H., Peck, M.A., Pinnegar, J.K., Drinkwater, K., Huret, M., and Nash, R.D.M. 2012b. Impacts of climate change on the complex life cycles of fish. Fisheries Oceanography, 22(2): 121-139.

Phillips, S.J., and Dudik, M. 2008. Modeling of species distributions with Maxent: new extensions and a comprehensive evaluation. Ecography, 31: 161-175.

Pikitch, E. K., Santora, C., Babcock, C.A., Bakun, A., Bonfil, R., Conover, D.O., Dayton, P., Doukakis, P., Fluharty, D., Heneman, B., Houde, E.D., Link, J., Livingston, P.A., Mangel, M., McAllister, M.K., Pope, J., and Sainsbury, K.J. 2004. Ecology: Ecosystembased fishery management. Science, 305: 346-347.

Pinnegar, J. K., Tomczak, M.T., and Link, J.S. 2014. How to determine the likely indirect foodweb consequences of a newly introduced non-native species: A worked example, Ecological Modelling, 272, 379-387.

Piroddi, C., Teixeira, H., Lynam, C.P., Smith, C., Alvarez, M.C., Mazik, K., Andonegi, E., Churilova, T., Tedesco, L., Chifflet, M., Chust, G., Galparsoro, I., Garcia, A.C., Maria Kämäri, M., Kryvenko, O., Lassalle, G., Neville, S., Niquil, N., Papadopoulou, N., Rossberg A.G., Suslin, V., Uyarra, M.C. 2015. Using ecological models to assess 
ecosystem status in support of the European Marine Strategy Framework Directive. Ecological Indicators, 58, 175-191

Plagányi, É.E. 2007. Models for an ecosystem approach to fisheries. FAO Fisheries Technical Paper. No. 477 Rome, FAO. 108 p.

Planque, B., Bellier, E., and Loots, C. 2011a. Uncertainties in projecting spatial distributions of marine populations. ICES Journal of Marine Science, 68(6): 1045-1050.

Planque, B., Loots, C., Petitgas, P., Lindstrom, U., and Vaz, S. 2011b. Understanding what controls the spatial distribution of fish populations using a multi-model approach. Fisheries Oceanography, 20: 1-17.

Pörtner, H.-O. 2012. Integrating climate-related stressor effects on marine organisms: unifying principles linking molecule to ecosystem-level changes. Marine Ecology Progress Series, 470: 273-290.

Pörtner, H.O., and Knust, R. 2007. Climate change affects marine fishes through the oxygen limitation of thermal tolerance. Science, 315: 95-97.

Pörtner, H.O., and Peck, M.A. 2010. Climate change impacts on fish and fisheries: towards a cause and effect understanding. Journal of Fish Biology, 77: 1745-1779.

Rabalais, N.N., Díaz, R.J., Levin, L.A., Turner, R.E., Gilbert, D., and Zhang, J. 2010. Dynamics and distribution of natural and human-caused coastal hypoxia. Biogeosciences, 7: 585619.

Rijnsdorp, A., Peck, M.A., Engelhard, G.H., Möllmann, C., and Pinnegar, J.K. 2009. Resolving the effect of climate change on fish populations. ICES Journal of Marine Science, 66: $1570-1583$.

Robinson, L.M., Elith, J., Hobday, A.J., Pearson, R.G., Kendall, B.E., Possingham, H.P. and Richardson, A.J. 2011. Pushing the limits in marine species distribution modelling: lessons from the land present challenges and opportunities. Global Ecology and Biogeography, 20: 789-802.

Rochette, S., Rivot, E., Morin, J., Mackinson, S., and Le Pape, O. 2010. Effect of nursery habitat degradation on flatfish population: Application to Solea solea in the Eastern Channel (Western Europe). Journal of Sea Research, 64: 34-44.

Rochette, S., Le Pape, O., Vigneau, J., and Rivot, E. 2013. A hierarchical Bayesian model for embedding larval drift and habitat models in integrated life cycle for exploited fish. Ecological Applications, 23: 1659-1676.

Rombouts, I., Beaugrand, G., Artigas, L.F., Dauvin, J.-C., Gevaert, F., Goberville, E., Kopp, D. Lefebvre, S., Luczak, C., Spilmont, N., Travers-Trolet, M., Villanueva, M.C., and Kirby, R.R. 2013. Evaluating marine ecosystem health: Case studies of indicators using direct observations and modelling methods. Ecological Indicators, 24: 353-365.

Rose, K.A., Allen, J.I., Artioli, Y., Barange, M., Blackford, J., Carlotti, F., Cropp, R., Daewel, U., Edwards, K., Flynn, K., Hill, S.L., HilleRisLambers, R., Huse, G., Mackinson, S., Megrey, B., Moll, A., Rivkin, R., Salihoglu, B., Schrum, C., Shannon, L., Shin, Y-J., Smith, S.L., Smith, C., Solidoro, C., St John, M., and Zhou, M. 2010. End-to-end models 
for the analysis of marine ecosystems: Challenges, issues, and next steps. Marine and Coastal Fisheries: Dynamics, Management, and Ecosystem Science, 2: 115-130.

Rose, K.A., James, H., Cowan Jr., Houde, E.D., Wang, S.B., and Young, J. 1999. An individualbased model of bay anchovy population dynamics in the mesohaline region of Chesapeake Bay. Marine Ecology Progress Series, 185: 113-132.

Rose, K.A. Fiechter, J., Curchitser, E.. et al., 2015. Demonstration of a fully-coupled end-to-end model for small pelagic fish using sardine and anchovy in the California Current. Progress in Oceanography, 138: 348-380.

Seebacher, F., and Franklin, C.E. 2012. Determining environmental causes of biological effects: the need for a mechanistic physiological dimension in conservation biology. Philosophical Transactions of the Royal Society B, 367: 1607-1614.

Sheldon, R.W., Prakash, A., and Sutcliff, Jr., W.H. 1972. The size distribution of particles in the ocean. Limnology and Oceanography, 17(3): 327-339.

Shin Y.-J., and Cury, P. 2001. Exploring fish community dynamics through size-dependent trophic interactions using a spatialized individual-based model. Aquatic Living Resources, 14: 65-80.

Shin, Y.-J., Shannon L.J., and Cury, P.M. 2004. Simulations of fishing effects on the southern Benguela fish community using an individual-based model: learning from a comparison with ECOSIM. In Ecosystem Approaches to Fisheries in the Southern Benguela. Shannon, L.J., Cochrane, K.L. and S.C. Pillar (Eds). African Journal of marine Science 26: 95-114.

Shurin, J.B., Borer, E.T., Seabloom, E.W., Anderson, K., Blanchette, C.A., Broitman, B., Cooper, S.D. and Halpen, B.S. 2002 A cross-ecosystem comparison of the strength of trophic cascades. Ecology Letters 5, 785-791.

Simons, S.L., Döring, R. and Temming, A. 2015. Combining area closures with catch regulations in fisheries with spatio-temporal variation: Bio-economic implications for the North Sea saithe fishery. Marine Policy 51, 281-292.

Simpson, S.D., Jennings, S., Johnson, M.P., Blanchard, J.L., Schön, P.J., Sims, D.W., and Genner, M.J. 2011. Continental shelf-wide response of a fish assemblage to rapid warming of the sea. Current Biology, 21 (18): 1565-1570.

Soberón, J. 2007. Grinnellian and Eltonian niches and geographic distributions of species. Ecol Lett 10:1115-1123

Solidoro, C., Pastres, R., Melaku Canu, D., Pellizzato, M., and Rossi, R. 2000. Modelling the growth of Tapes philippinarum in Northern Adriatic lagoons. Marine Ecology Progress Series, 199: 137-148.

Speirs, D.C., Guirey, E.J., Gurney, W.S.C., and Heath, M.R. 2010. A length-structured partial ecosystem model for cod in the North Sea. Fisheries Research, 106(3): 474-494.

Steenbeek, J., Coll, M., Gurney, L., Mélin, F., Hoepffner, N., Buszowski, J., and Christensen, V. 2013. Bridging the gap between ecosystem modelling tools using geographic information systems: driving a food-web model with spatial-temporal primary production data. Ecological Modelling, 263: 139-151. 
Stips, A., Bolding, K., Pohlman, T., and Burchard, H. 2004. Simulating the temporal and spatial dynamics of the North Sea using the new model getm, General Estuarine Transport Model). Ocean Dynamics, 54: 266-283.

Stock, C.A., Alexander, M.A., Bond, N.A., Brander, K.M., Cheung, W.W.L., Curchitser, E.N., et al. 2011. On the use of IPCC-class models to assess the impact of climate on Living Marine Resources. Progress in Oceanography, 88: 1-27.

Sugihara, G., May, R., Ye, H., Hsieh, C.-h., Deyle, E., Fogarty, M., and Munch, S. 2012. Detecting causality in complex ecosystems. Science, 338: 496-500.

Sumaila, U.R., Cheung, W.W.L., Lam, V.W.Y., Pauly, D., and Herrick, S. 2011. Climate change impacts on the biophysics and economics of world fisheries. Nature Climate Change, 1: 449-456.

Sunday, J.M., Bates, A.E., and Dulvy, N.K. 2012. Thermal tolerance and the global redistribution of animals. Nature Climate Change, 2: 686-690.

Sundby, S. 2000. Recruitment of Atlantic cod stocks in relation to temperature and action of copepod populations. Sarsia, 85: 277-298.

Sykes, M.T., Prentice, I.C., and Cramer, W. 1996. A bioclimatic model for the potential distributions of north European tree species under present and future climates. Journal of Biogeography, 23: 203-233.

Taylor, A., Allen, J., and Clark, P. 2002. Extraction of a weak climatic signal by an ecosystem. Nature, 416: 629-632.

Teal, L., Marras, S., Peck, M.A., amd Domenici, P. In Press. Physiological-based approaches to characterize fish habitat suitability: Their usefulness and limitations. Estuarine Coastal and Shelf Science. doi:10.1016/j.ecss.2015.11.014

Teal, L.R., Van Hal, R., Van Kooten, T., Ruardij, P., and Rijnsdorp, A.D. 2012. Bio-energetics underpins the spatial response of North Sea plaice (Pleuronectes platessa L.) and sole (Solea solea L.) to climate change. Global Change Biology, 18: 3291-3305.

Temming, A., Floeter, J., and Ehrich, S. 2007. Predation hot spots: large scale impact of local aggregations. Ecosystems, 10: 865-876.

Thomas, L., Buckland, S.T., Newman, K.B., and Harwood, J. 2005. A unified framework for modelling wildlife population dynamics. Australian and New Zealand Journal of Statistics, 47: 19-34.

Thuiller, W. 2003. BIOMOD - optimizing predictions of species distributions and projecting potential future shifts under global change. Global Change Biology, 9: 1353-1362.

Travers, M., Shin Y.-J., Jennings S., Machu, E., Huggett, J.A., Field, J., and Cury P. 2009. Twoway coupling versus one-way forcing of plankton and fish models to predict ecosystem changes in the Benguela. Ecological Modelling, 220: 3089-3099.

Travers, M., Shin, Y.-J., Jennings, S., and Cury, P. 2007. Towards end-to-end models for investigating the effects of climate and fishing in marine ecosystems. Progress in Oceanography, 75: 751-770. 
Travers, M., Watermeyer K., Shannon L.J., and Shin Y.-J. 2010. Changes in food web structure under scenarios of overfishing in the southern Benguela: comparison of the Ecosim and OSMOSE modelling approaches. Journal of Marine Systems, 79: 101-111.

van der Veer, H.W., Cardoso, J.F.M.F., Peck, M.A., and Kooijman, S.A.L.M. 2009. Physiological performance of plaice Pleuronectes platessa (L.): A comparison of static and dynamic energy budgets. Journal of Sea Research, 62: 83-92.

VECTORS (2014) Scenario modelling of the North Sea under the influence of multiple drivers with recommendations for regional adaptive management strategies addressing EU policies. VECTORS Deliverable Report 4.2.2. (www.marinevectors.eu/deliverables/D4_2_2.pdf).

Walters, C., Martell, S.J.D., Christensen, V., and Mahmoudi, B. 2008. An Ecosim model for exploring Gulf of Mexico ecosystem management options: Implications of including multistanza life-history models for policy predictions. Bulletin of Marine Science, 83: 251-271.

Werner, F., Quinlan, J., Lough, R., and Lynch, D. 2001. Spatially-explicit individual based modeling of marine populations: a review of the advances in the 1990s. Sarsia, 86: 411421.

Yemane, D., Shin, Y.-J., and Field, J. 2009. Exploring the effect of marine protected areas on the dynamics of fish communities in the southern Benguela: an Individual Based Modelling approach. ICES Journal of Marine Science, 66: 378-387. 
Table 1: Summary of characteristics of 11, spatially-explicit models providing estimates of changes in the distribution and/or productivity of living marine resources including strengths weaknesses in different categories as perceived by the authors of this study. In most cases, developers and users of these models contributed to the ratings. However, the ratings are based on the authors' opinion. Therefore, comparison across modelling approaches is not warranted. The right column provides a description of the colour scheme (Green, Yellow, Red). BEM = Bioclimate Envelope Model), IBM = Individual-based Model, FW $=$ food web, SSpectrum = size spectrum. All other acronyms and abbreviations are defined in the text.

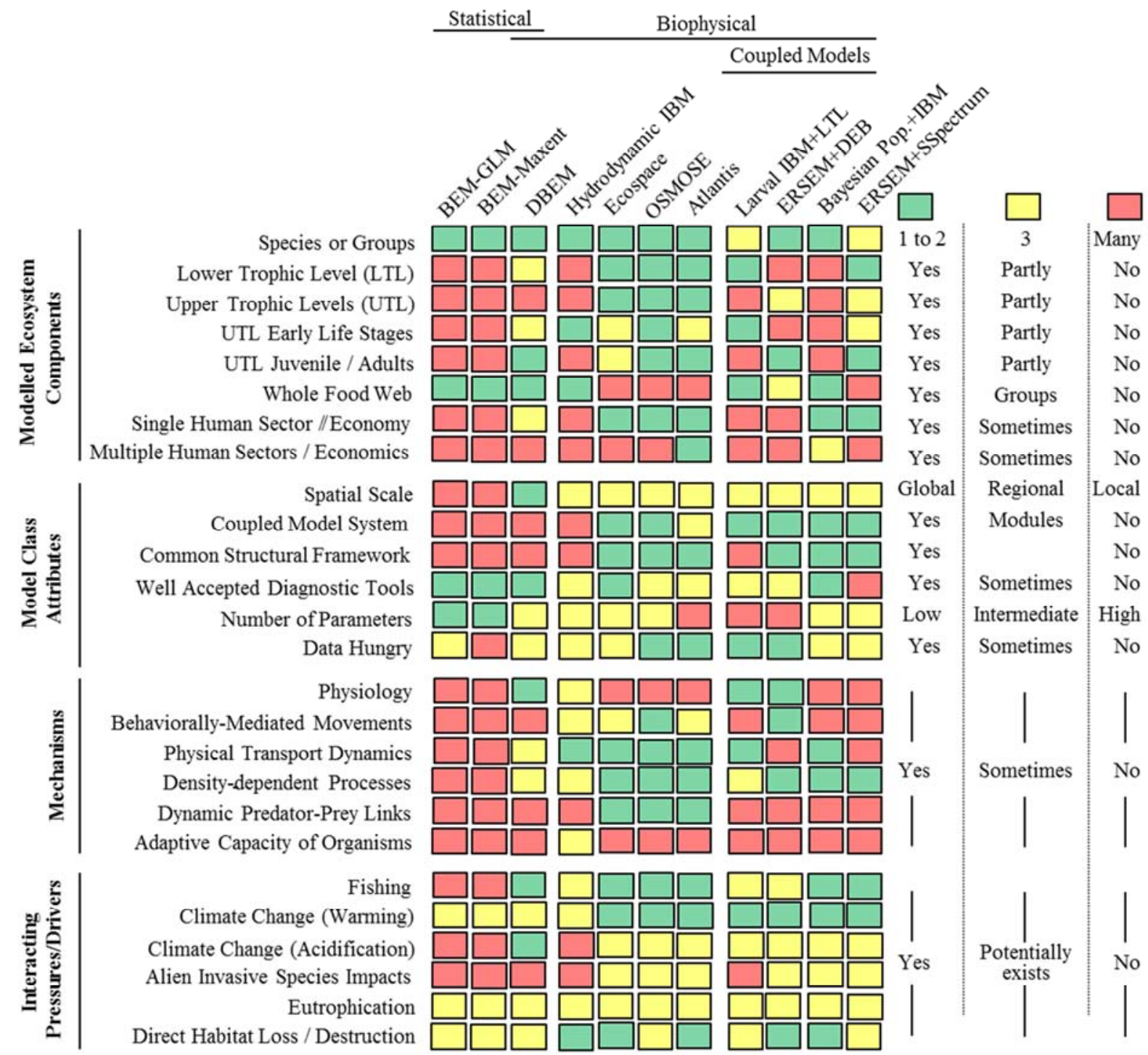




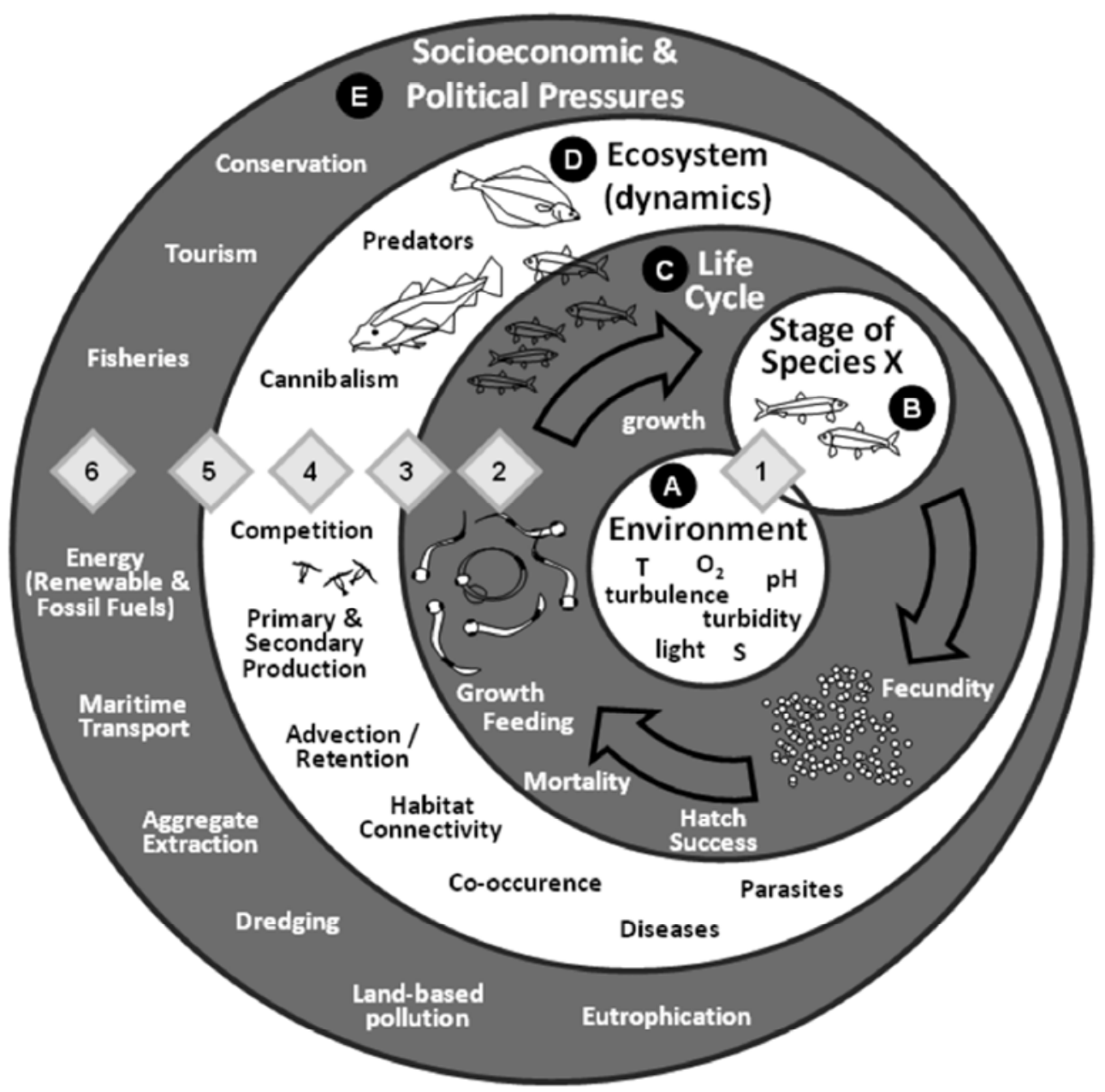

Figure 1) Schematic of the increase in complexity in pressures and factors that can be taken into account using different modelling techniques. The innermost (A) circle depicts key abiotic features of marine environements. Subsequent circles represent increasing levels of complexity including a specific life stage of a single species (B), lifecycle dynamics of a single species (C, Stage-based and IBMs), interactions among species in food webs (D) and the impacts of various pressures on marine organisms and habitats (E). Small diamonds reflect different types of modelling including statistical models examining relationships between environment factors, single species (1), biophysical models examining various life stages (2, IBMs) often including some additional trophic levels (3, LTL-IBM, LTL-Size Spectrum), models simulating food webs (4, Size Spectrum, ECOSPACE, OSMOSE, ERSEM-DEB) and end-to-end models that simulate the whole food web as well as impacts of pressures related to single (5, ISIS Fish, FishRent) or mulitple (6, Atlantis) economic sectors. A management strategy evaluation framework has been included within some coupled or end-to-end model approaches (ECOSIM, Atlantis). 


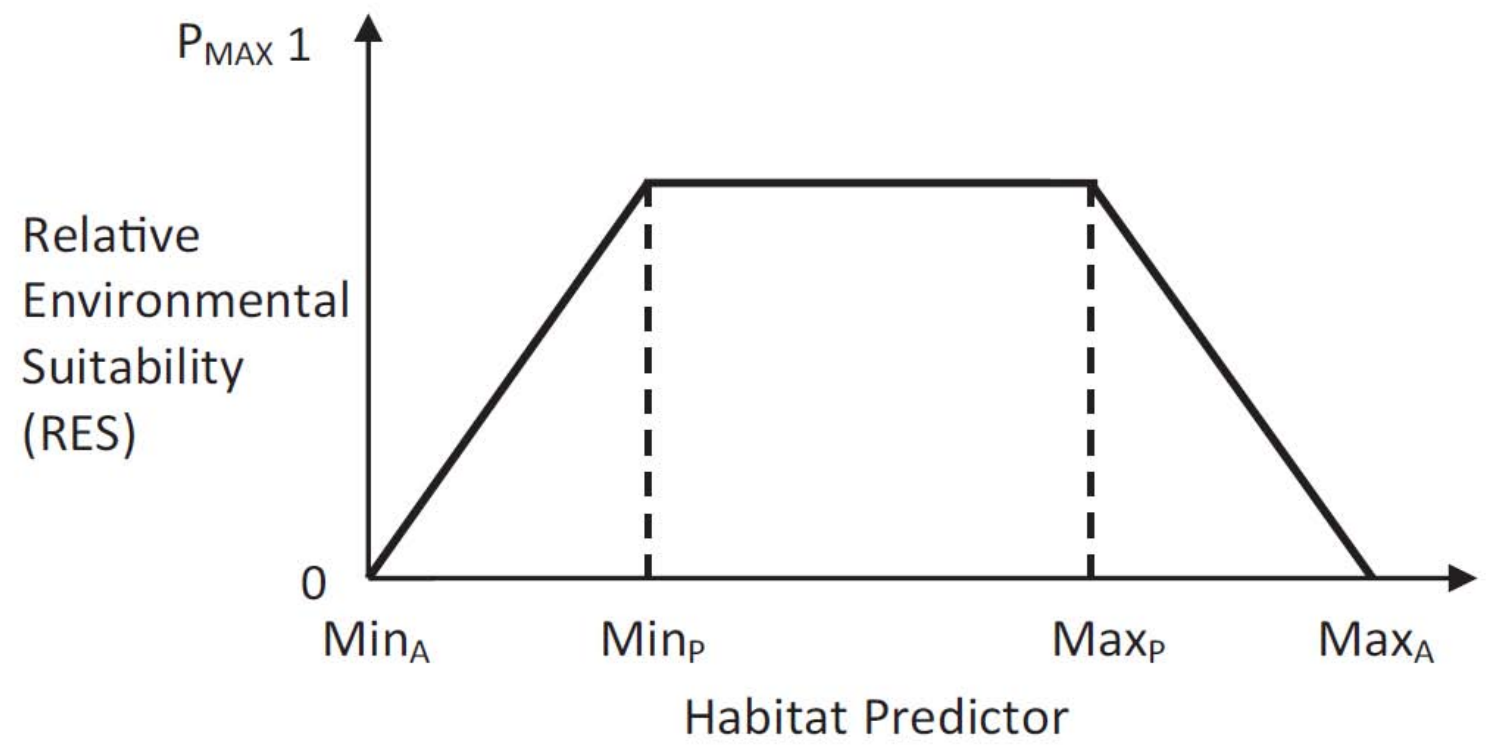

Figure 2) Trapezoidal species' response curve used in bioclimate envelope modelling of the AquaMaps type, showing absolute minimum $\left(\operatorname{Min}_{\mathrm{A}}\right)$ and maximum $\left(\operatorname{Max}_{\mathrm{A}}\right)$ and preferred minimum $\left(\operatorname{Min}_{\mathrm{P}}\right)$ and maximum $\left(\mathrm{Max}_{\mathrm{P}}\right)$ levels of a habitat predictor, and the relative environmental suitability, the highest obtainable value being ( $\left.\mathrm{P}_{\mathrm{Max}}\right)$ (see Jones et al., 2012). 


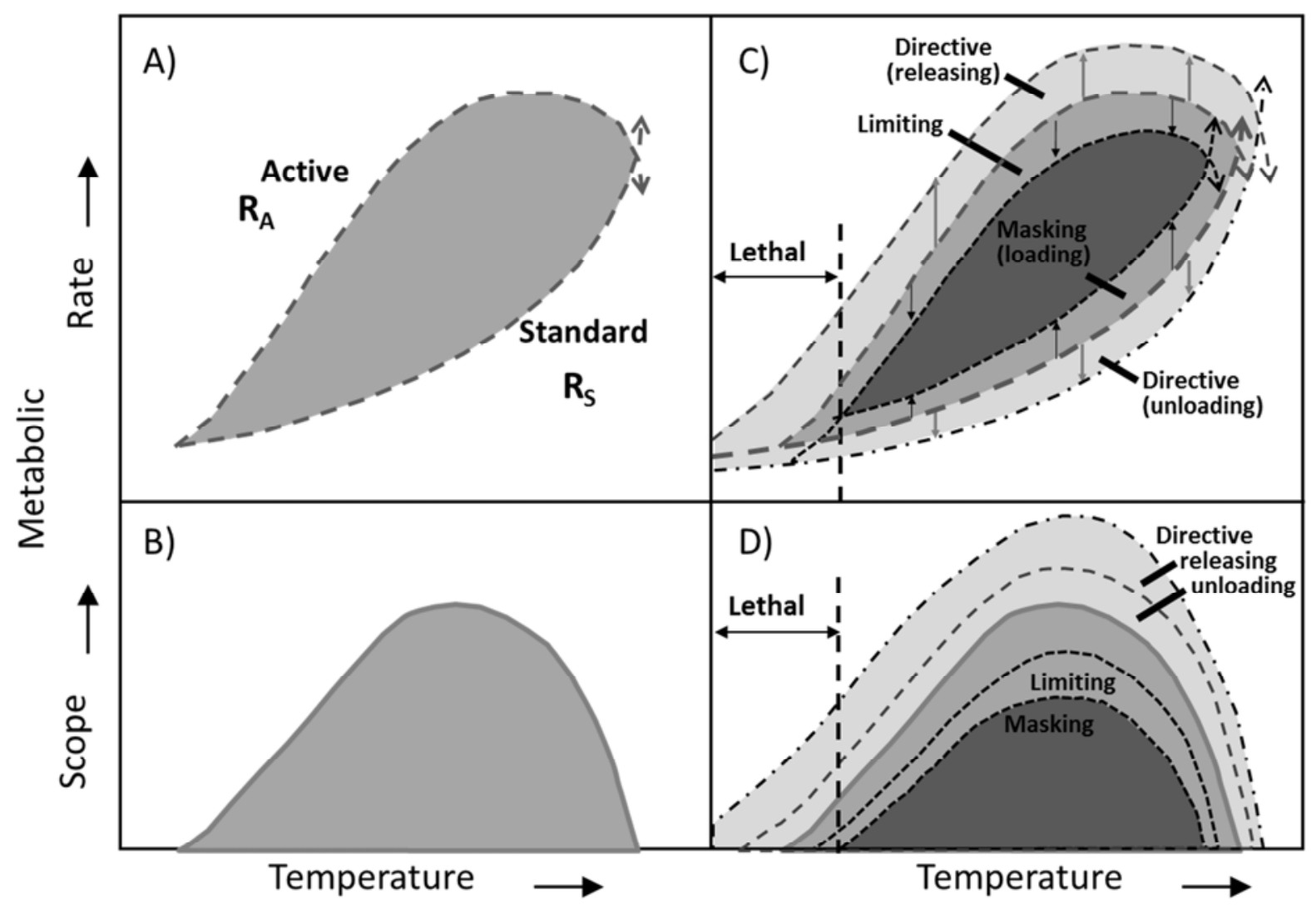

Figure 3) Changes in standard metabolic rate $\left(R_{S}\right)$ and active metabolic rate $\left(R_{A}\right)$ with temperature and the metabolic scope $\left(R_{A^{-}}-R_{S}\right)$ versus temperature (Panels $\left.A \& B\right)$. The right panels indicate increases or decreases in metabolic rate (panel $\mathrm{C}$ ) and scope (panel D) due to the interaction of other environmental factors superimposed on the controlling effect of temperature. The interacting factors can either reduce or expand the range of tolerable (lethal) temperatures by either decreasing (loading) or increasing (unloading, releasing) metabolic scope (based on Fry, 1957, 1971). 


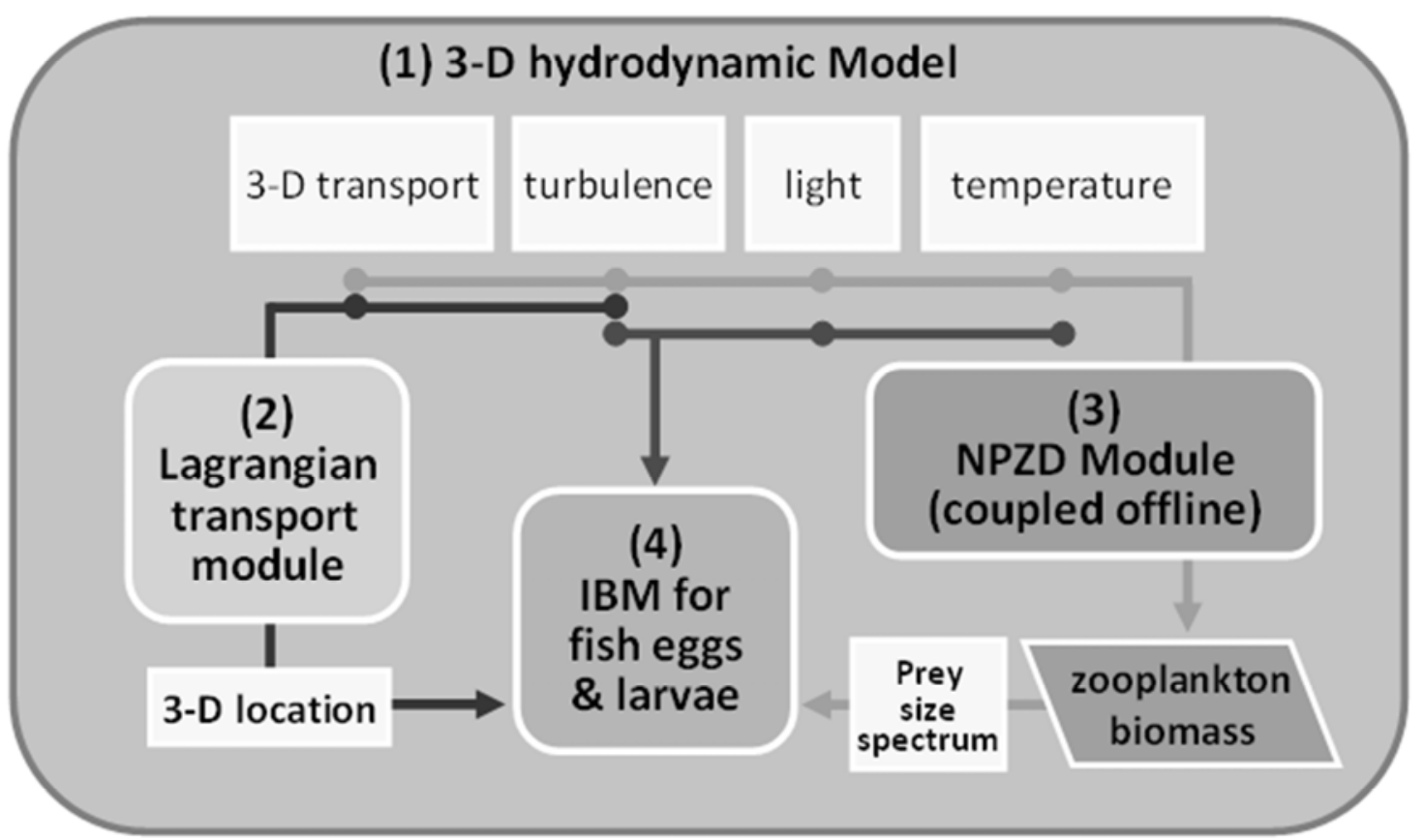

Figure 4) Coupled biophysical model for passive (planktonic) life stages of marine fish. Various models include: 1) a physical (hydrodynamic) model core, 2) particle tracking model, 3) lower trophic level ecosystem model (nutrient, phytoplankton, zooplankton and detritus (NPZD), etc.), and 4) an individual-based model (IBM) for larval fish (foraging, physiology, etc.). A sizeresolved prey field is derived from bulk zooplankton carbon using size spectrum theory. This scheme was adapted from Daewel et al. (2011). 


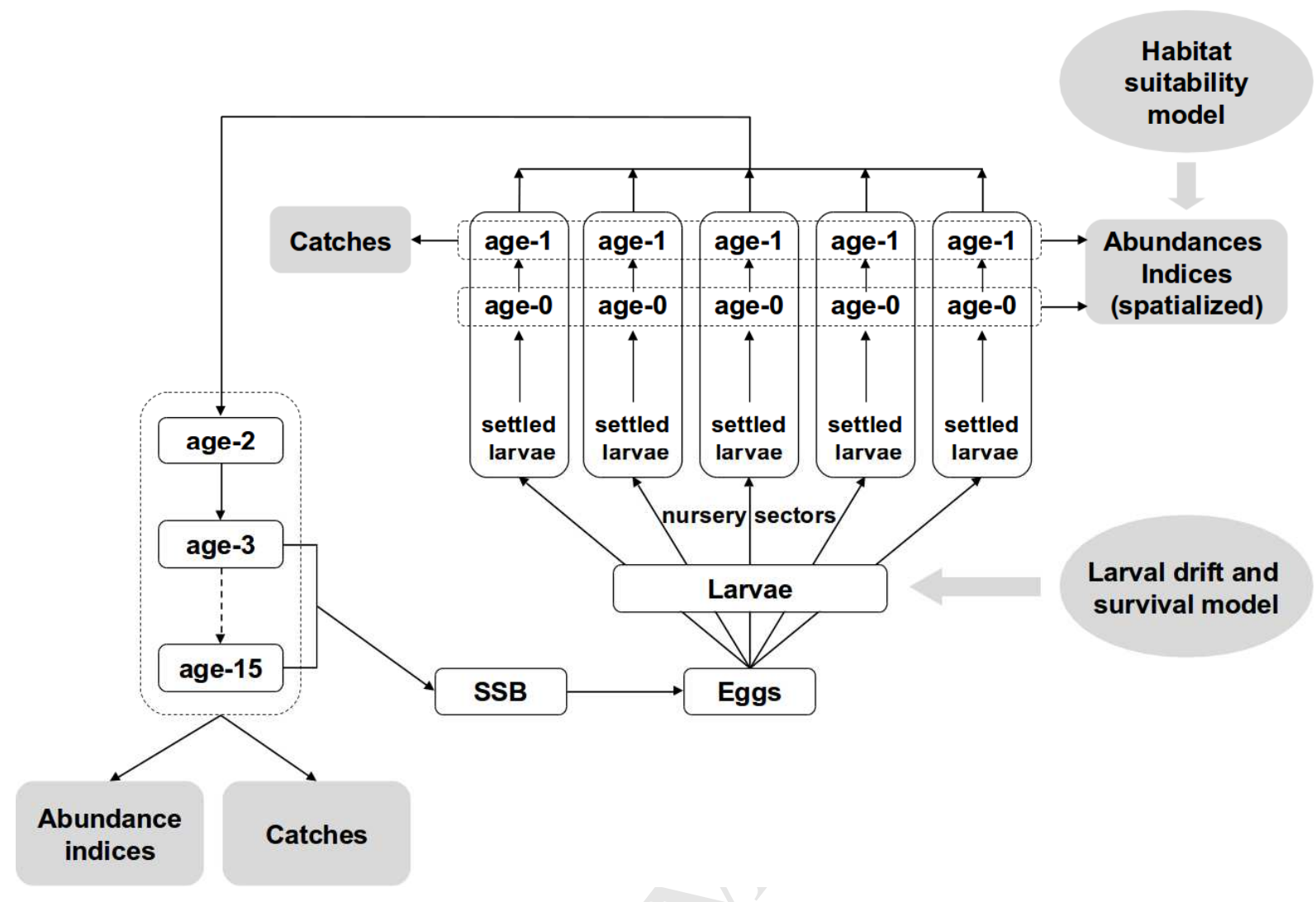

Figure 5) Scheme of a hierarchical, Bayesian full life-cycle model used to examine flatfish species. White boxes represent the hidden population dynamic model and grey boxes represent processes and observations. The two ellipses with large arrows represent inputs from other models (see Rochette et al., 2013) 


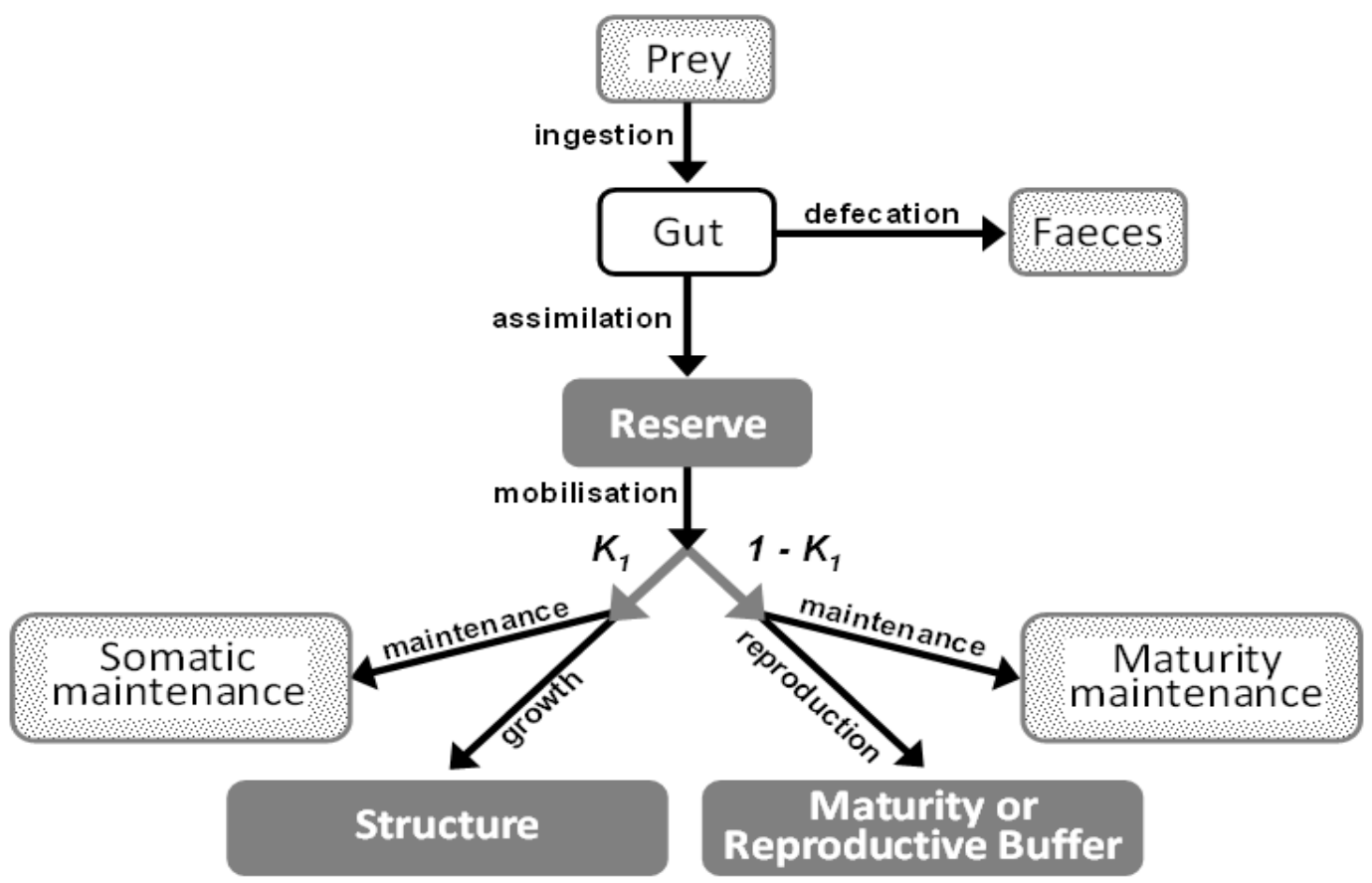

Figure 6) A schematic representation of the standard dynamic energy budget (DEB) model showing the paths of energy flow through an organism. The light shaded boxes represent sources or sinks of energy, the dark shaded boxes indicate the three state variables describing the organism. Processes affecting energy flows are described by black arrows (see Teal et al., 2012). A particularly attractive feature of these models is the use of allocation rules (proportion $\mathrm{K}_{1}$ ) to partition energy reserves among various processes such as somatic versus gonadal / reproduction maintenance and growth). 


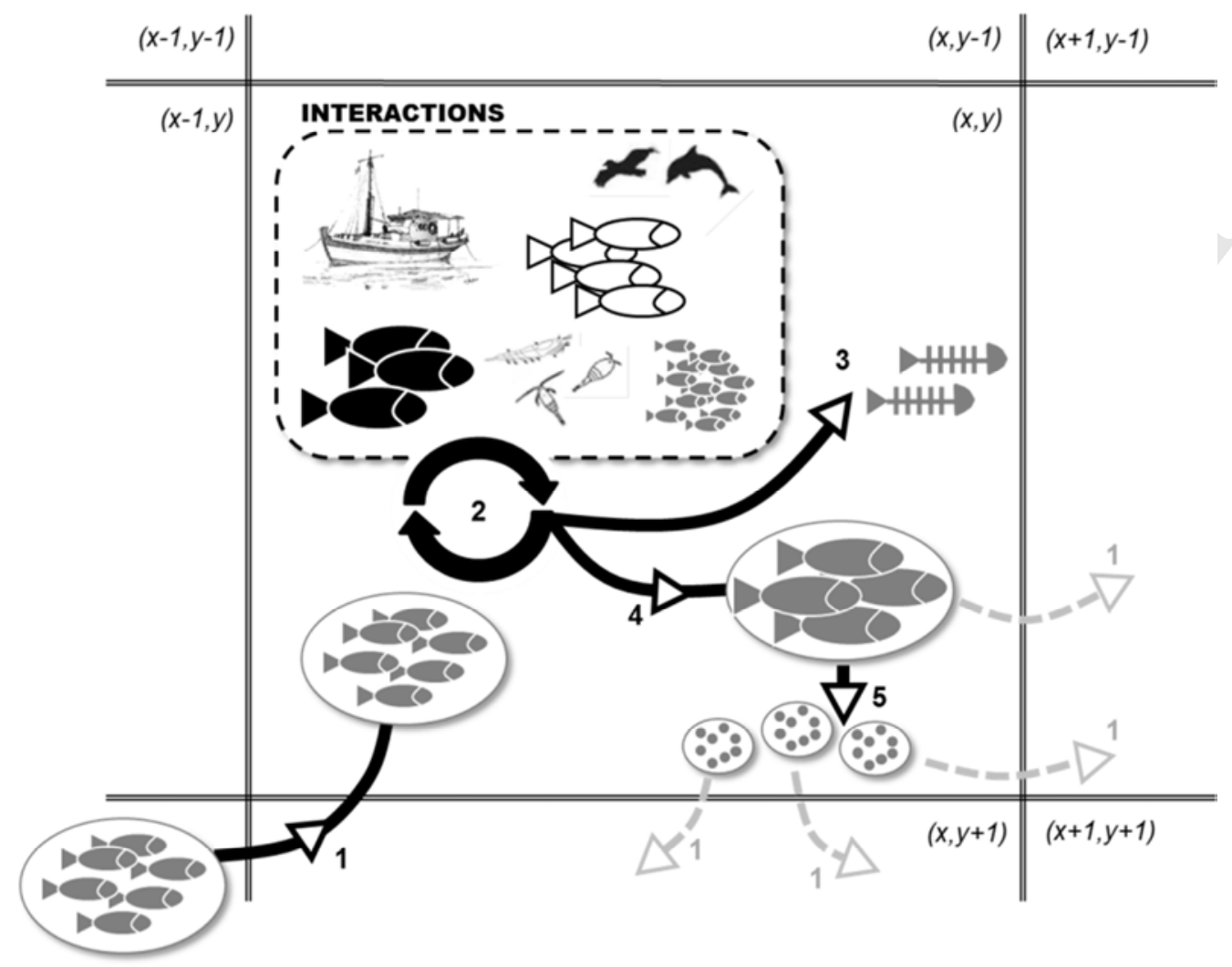

Figure 7) Diagram of spatial interactions with a grid box of the OSMOSE model. Processes occuring within each grid cell include: (1) movement (either random or data-driven), losses of individuals within superparticles driven by (2) predation mortality [which is separated into three components: i), explicit predation mortality, ii) other natural mortality (including that due to top predators), and iii) losses due to fishing activities], (3) starvation, (4) growth, and (5) reproduction and recruitment (see Travers et al., 2010). 


\section{Physical Drivers}

\section{Ecological Processes}

Socio-Economic Drivers

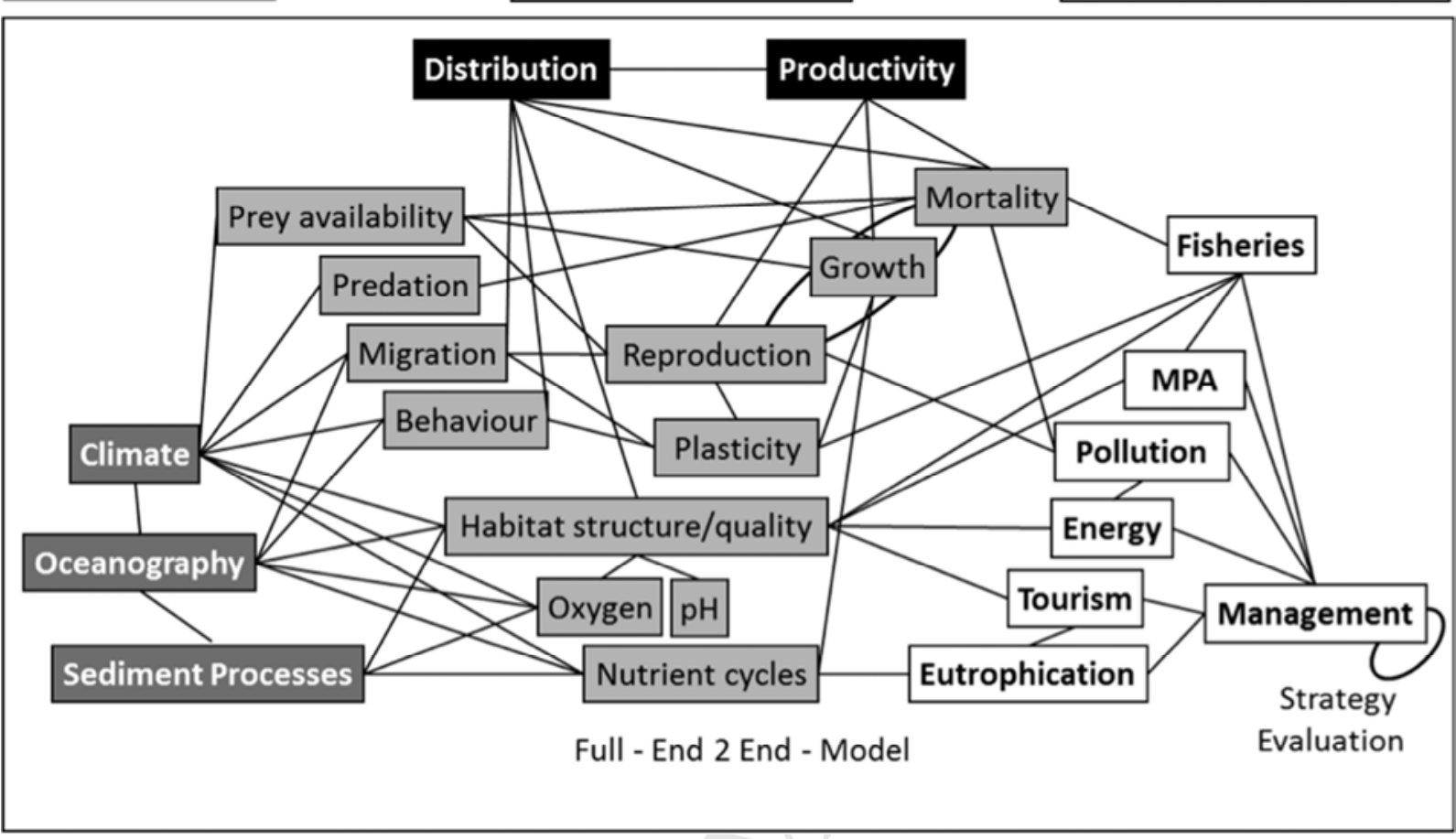

Figure 8) Physical and socio-economic drivers and ecological processes included in the end-toend (E2E) model ATLANTIS (Fulton, 2010). This spatially-explicit model includes three physical drivers and six socio-economic drivers with the latter linked to a management strategy evaluation framework. An invasive species module also exists (not shown). 